\title{
Super-Twisting Sliding Mode Control for Gearless PMSG-Based Wind Turbine
}

\author{
Mojtaba Nasiri $\mathbb{D},{ }^{1}$ Saleh Mobayen $\mathbb{D}^{2},{ }^{2}$ and Quan Min Zhu $\mathbb{D}^{3}$ \\ ${ }^{1}$ Department of Electrical Engineering, Faculty of Engineering, Abhar Branch, Islamic Azad University, Abhar, Iran \\ ${ }^{2}$ Advanced Control Systems Laboratory, Department of Electrical Engineering, University of Zanjan, University Blvd., \\ 45371-38791, Zanjan, Iran \\ ${ }^{3}$ Department of Engineering Design and Mathematics, University of the West of England, Bristol, UK \\ Correspondence should be addressed to Mojtaba Nasiri; m_nasiri@aut.ac.ir
}

Received 22 January 2019; Revised 26 March 2019; Accepted 11 April 2019; Published 22 April 2019

Academic Editor: Hassan Zargarzadeh

Copyright (C 2019 Mojtaba Nasiri et al. This is an open access article distributed under the Creative Commons Attribution License, which permits unrestricted use, distribution, and reproduction in any medium, provided the original work is properly cited.

\begin{abstract}
In recent years, the complexities of wind turbine control are raised while implementing grid codes in voltage sag conditions. In fact, wind turbines should stay connected to the grid and inject reactive power according to the new grid codes. Accordingly, this paper presents a new control algorithm based on super-twisting sliding mode for a gearless wind turbine by a permanent magnet synchronous generator (PMSG). The PMSG is connected to the grid via the back-to-back converter. In the proposed method, the machine side converter regulates the DC-link voltage. This strategy improves low-voltage ride through (LVRT) capability. In addition, the grid side inverter provides the maximum power point tracking (MPPT) control. It should be noted that the supertwisting sliding mode (STSM) control is implemented to effectively deal with nonlinear relationship between DC-link voltage and the input control signal. The main features of the designed controller are being chattering-free and its robustness against external disturbances such as grid fault conditions. Simulations are performed on the MATLAB/Simulink platform. This controller is compared with Proportional-Integral (PI) and the first-order sliding mode (FOSM) controllers to illustrate the DC-link voltage regulation capability in the normal and grid fault conditions. Then, to show the MPPT implementation of the proposed controller, wind speed is changed with time. The simulation results show designed STSM controller better performance and robustness under different conditions.
\end{abstract}

\section{Introduction}

Recently, wind energy is a rapidly growing source of electricity $[1,2]$. Installed wind power generation is expected to exceed $760 \mathrm{GW}$ by 2020 in the world [3]. Therefore, the significant amount of power generation capacity belongs to wind power. In the past, wind farms could be disconnect from the grid in the grid side fault conditions, but nowadays, the modern grid codes, in addition to not allowing the separation of the grid to wind turbines, require them to perform some auxiliary tasks in grid fault conditions. For instance, Danish grid code forces wind farm to follow low-voltage ride through (LVRT) requirements in fault condition according to Figure 1 [4].

Among different types of wind turbines, doubly fed induction generators (DFIGs) and permanent magnet synchronous generators (PMSGs) are of attractive types in wind farms [5]. Due to advantages, developments in semiconductor switching devices and high-reliability and efficiency, the use of PMSG is growing.

In traditional control of back-to-back converter, machine side converter (MSC) performs the maximum power point tracking (MPPT) and the grid side converter (GSC) regulates the DC-link voltage $[6,7]$. Hence, when grid faults occurred, the DC-link voltage may be increased because MSC does not sense grid fault and GSC loses its own control on DC-link voltage regulation [8]. To overcome this problem, the GSC and MSC tasks can be changed $[9,10]$. Due to the nonlinear relationship between DC-link voltage and input control signal, different nonlinear controls are presented [11, 12].

Among the modern nonlinear control, sliding mode control has good feature because it is robust with respect to system parameter uncertainties and external disturbances [13]. The main drawback of conventional sliding mode 
U Point of Connection

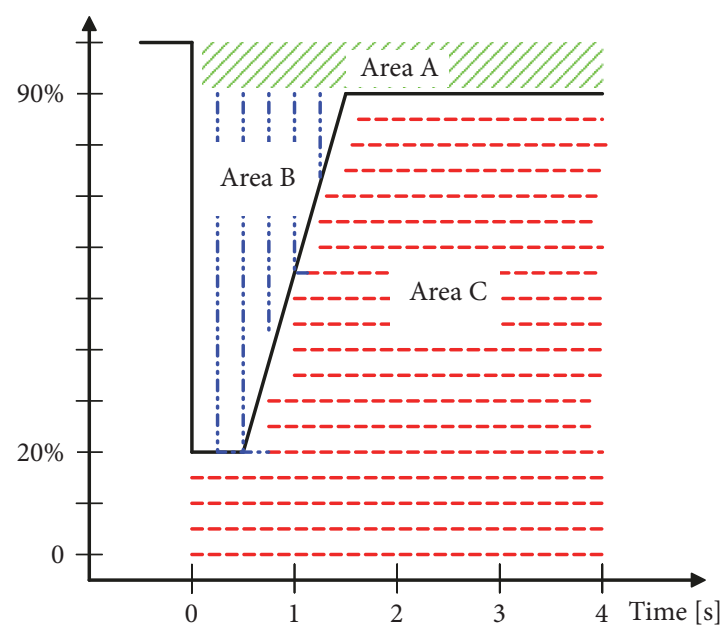

(a)

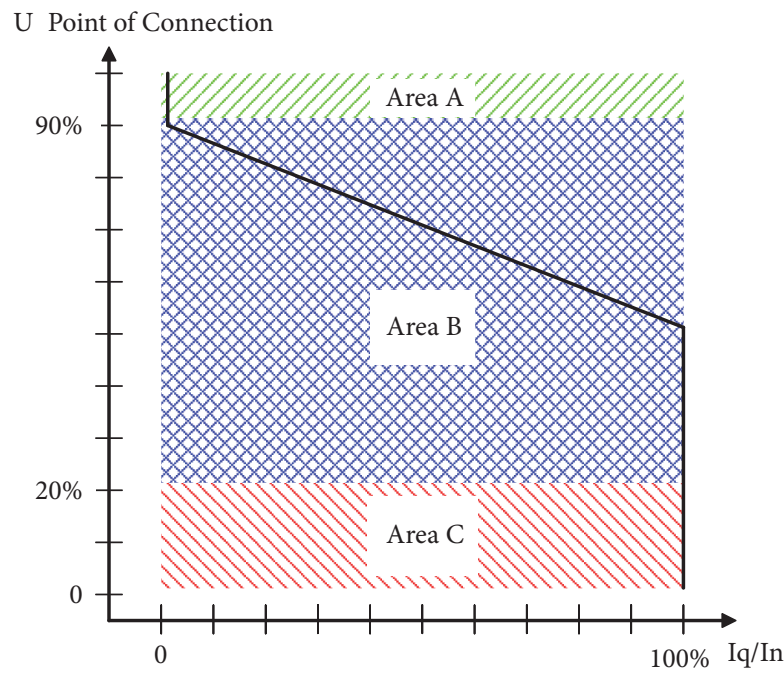

(b)

FIGURE 1: The LVRT requirements in Danish grid code.

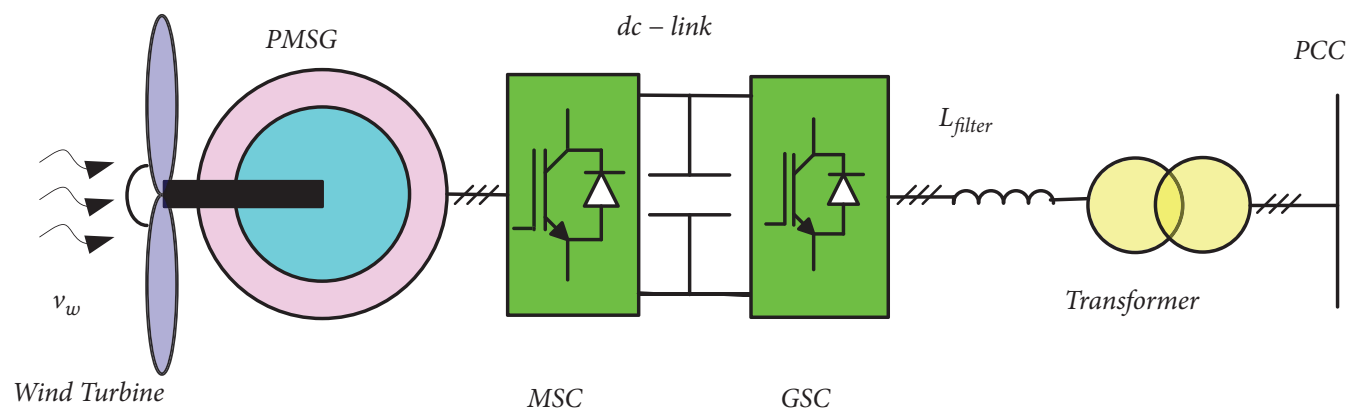

FIGURE 2: The PMSG-based wind power system configuration.

control is chattering. To reduce chattering, several methods are introduced. One of the attractive chattering-free sliding modes is high order sliding mode (HOSM) [14, 15]. But the main problem in the implementation of HOSM algorithms is the increasing information demand. The super-twisting sliding mode (STMC) is one of HOSM that does not need additional information $[16,17]$.

Several papers use the HOSM to enhance LVRT capability in PMSG-based wind turbines [18-20]. Nevertheless, all of these works use traditional control of back-to-back converters. In fact, they cannot keep the DC-link voltage in safe range in deep voltage drops. Therefore, they need to use external devices which result in the overall cost increases. As mentioned before, by exchanging the task of converters, the DC-link voltage is kept in safe range, MSC regulates DC-link voltage, and GSC controls MPPT. In present paper, the supertwisting sliding mode control method is employed in the new control structure.

It can be mentioned that the new contribution of the proposed method is implementing a HOSM controller for the gearless high inertia PMSG-based wind turbine, in which no additional instrument is required to implement LVRT without imposing stress to the DC-link capacitor. In fact, the grid voltage drop and the wind variations are considered as an external disturbance. Furthermore, the chattering is eliminated and the controller does not need additional information.

In this paper, wind energy conversion system model, including modeling of the wind turbine, PMSG, DC-link, and the grid is presented in Section 2. In Section 3, first, the brief review of STSMC is presented; then full STSM controllers for back-to-back converters are designed. Section 4 proves the improvement of the new control strategy by comparing with the conventional approach on the MATLAB/Simulink. Finally, in Section 5, conclusions are presented.

\section{Description of Wind Energy Conversion System}

The schematic of the PMSG wind power system is shown in Figure 2. The modeling of each section has been introduced in the following subsections.

2.1. Modeling of Wind Turbine. The mechanical output power of wind turbine is given by the following equation:

$$
P_{\text {Tur }}=0.5 \rho \pi r^{2} C_{p}(\lambda, \beta) v_{w}^{3}
$$


The turbine power coefficient is defined by the following equations [21]:

$$
\begin{aligned}
C_{p}(\lambda, \beta)= & 0.5176\left(\frac{116}{\lambda_{i}}-0.4 \beta-5\right) \exp ^{\left(-21 / \lambda_{i}\right)} \\
& +0.0068 \lambda \\
\frac{1}{\lambda_{i}}= & \frac{1}{\lambda+0.08 \beta}-\frac{0.035}{\beta^{3}+1}
\end{aligned}
$$

The tip-speed ratio $(\lambda)$ depends on the shaft speed $\left(\omega_{\mathrm{m}}\right)$ and the wind speed as given below:

$$
\lambda=\frac{r \omega_{m}}{v_{w}}
$$

From (1) and (4), the turbine torque is given as

$$
T_{\text {Tur }}=0.5 \rho \pi r^{2} \frac{C_{p}(\lambda, \beta)}{\lambda} v_{w}^{2}
$$

The equation of motion of single-mass modeling of the mechanical system is expressed as

$$
\frac{d \omega_{m}}{d t}=\frac{1}{J_{e q}}\left(T_{T u r}-T_{e}-B_{e q} \omega_{m}\right)
$$

where $\mathrm{T}_{\mathrm{e}}$ is the electromagnetic torque of the generator.

2.2. Modeling of PMSG. A dynamic mathematical model of a surface-mounted PMSG is presented in the synchronous $d-q$ equivalent circuits as [22]

$$
\begin{aligned}
& \frac{d i_{d s}}{d t}=\frac{1}{L_{s}}\left(-R_{s} i_{d s}+\omega_{e} L_{s} i_{q s}+V_{d s}\right) \\
& \frac{d i_{q s}}{d t}=\frac{1}{L_{s}}\left(-R_{s} i_{q s}-\omega_{e} L_{s} i_{d s}-\omega_{e} \psi+V_{q s}\right)
\end{aligned}
$$

The electromagnetic torque from the generator is given as

$$
T_{e}=\frac{3}{2} \frac{p}{2} \psi i_{q s}
$$

2.3. Modeling of DC-Link. The DC-link is the interface between the generator and the grid. The dynamic DC-link voltage equation can be expressed by

$$
\frac{d}{d t}\left(\frac{V_{d c}^{2}}{2}\right)=\frac{1}{C}\left(-\frac{3}{2} \frac{p}{2} \psi \omega_{m} i_{q s}-P_{\text {loss }}-P_{g r i d}\right)
$$

where $P_{\text {loss }}$ and $P_{\text {grid }}$ are the generator and the back-to-back converters losses and the grid power, respectively. In this study, it is supposed that converters are lossless.

2.4. Modeling of Grid. The GSC is connected to the point of common coupling (PCC) by $R L$ grid filter and a coupling transformer. In this study, it is modeled by RL that the state equations in the $d$-q reference frame can be expressed as

$$
\begin{aligned}
& \frac{d i_{d f}}{d t}=\frac{1}{L_{f}}\left(-R_{f} i_{d f}+\omega_{f} L_{f} i_{q f}+e_{d f}-V_{d f}\right) \\
& \frac{d i_{q f}}{d t}=\frac{1}{L_{f}}\left(-R_{f} i_{q f}-\omega_{f} L_{f} i_{d f}+e_{q f}-V_{q f}\right)
\end{aligned}
$$

where $\omega_{f}$ is the angular frequency.

The equations of instantaneous injected active and reactive powers to the PCC are expressed as

$$
\begin{aligned}
P_{P C C} & =\frac{3}{2}\left(V_{d f} i_{d f}+V_{q f} i_{q f}\right) \\
Q_{P C C} & =\frac{3}{2}\left(V_{q f} i_{d f}-V_{d f} i_{q f}\right)
\end{aligned}
$$

If the PCC voltage space vector is oriented on d-axis, $V_{q f}=0$, then

$$
\begin{aligned}
P_{P C C} & =\frac{3}{2} V_{d f} i_{d f} \\
Q_{P C C} & =-\frac{3}{2} V_{d f} i_{q f}
\end{aligned}
$$

Now, let us introduce the state variables $x_{1}=\omega_{m}, x_{2}=i_{d s}$, $x_{3}=i_{q s}, x_{4}=0.5 V_{d c}^{2}, x_{5}=i_{d f}, x_{6}=i_{q f}$.

The state-space equations obtained up to now are put together to obtain a state-space model of the whole system. It is supposed that the MSC and GSC are ideal and they produce the desired voltages. In fact, the average model is used for GSC and MSC. For convenience, the state-space models of the whole system are rewritten as

$$
\begin{aligned}
& \dot{x}_{1}=\frac{1}{J_{e q}}\left(T_{T u r}-\frac{3}{2} \frac{p}{2} \psi x_{3}-B_{e q} x_{1}\right) \\
& \dot{x}_{2}=\frac{1}{L_{s}}\left(-R_{s} x_{2}+\frac{p}{2} L_{s} x_{1} x_{3}+V_{d s}\right) \\
& \dot{x}_{3}=\frac{1}{L_{s}}\left(-R_{s} x_{3}-\frac{p}{2} L_{s} x_{1} x_{2}-\frac{p}{2} \psi x_{1}+V_{q s}\right) \\
& \dot{x}_{4}=\frac{1}{C}\left(-\frac{3}{2} \frac{p}{2} \psi x_{1} x_{3}-P_{\text {loss }}-P_{g r i d}\right) \\
& \dot{x}_{5}=\frac{1}{L_{f}}\left(-R_{f} x_{5}+\omega_{f} L_{f} x_{6}+e_{d f}-V_{d f}\right) \\
& \dot{x}_{6}=\frac{1}{L_{f}}\left(-R_{f} x_{6}-\omega_{f} L_{f} x_{5}+e_{q f}\right)
\end{aligned}
$$

\section{Control of Back-to-Back Converters}

In this section, new controllers for the back-to-back converters are designed using second-order sliding mode. Among several proposed modern techniques, the sliding mode provides more advantages such as robustness and high-accuracy solution especially for nonlinear systems under uncertainty 
conditions and external disturbances [23]. The main disadvantage of the classic sliding mode is the chattering problem. Though, the second-order sliding mode is appropriate to obtain chattering-free control and guarantees a finite-time reaching phase [24]. In Section 3.1, second-order sliding modes are briefly introduced, then, in Section 3.2, supertwisting controller that is one of attractive second-order sliding mode controllers will be presented.

3.1. A Brief Introduction of Second-Order Sliding Modes. As mentioned before, the main disadvantage of first-order sliding mode control (FOSMC) is a chattering problem. This effect consists of the oscillation of the system variables around the sliding surface, which causes a discontinuous control signal. This effect can disturb or damage the physical system. One of the interesting ways to eliminate or reduce chattering effect is using HOSM. In this technique, the higher order time derivatives of sliding surface keep to zero [24]. As a result, this action mitigates the chattering effect. But, the increasing information demand is the main problem in the implementation of HOSM algorithms. Generally, $r$-th order sliding controller requires the knowledge of $(r-1)$-th order of time derivative. Thus, a $r$-th order sliding mode is determined by

$$
\sigma=\dot{\sigma}=\ddot{\sigma}=\cdots=\sigma^{(r-1)}=0
$$

Hence, the second-order sliding mode controller is simple. In fact, it needs the knowledge of the first-order time derivative of the sliding surface. These controllers require real-time measurement of $\dot{\sigma}$ or at least of $\operatorname{sign}(\dot{\sigma})$.

Among several second-order sliding mode controllers, the super-twisting controller has a good feature because it does not need the knowledge of $\dot{\sigma}$. The super-twisting controller can be used instead of the first-order (conventional) sliding mode using the same available information.

3.2. Super-Twisting Controller. Consider the nonlinear dynamic system given by [24]

$$
\begin{aligned}
& \dot{x}=a(t, x)+b(t, x) u, \\
& \sigma=\sigma(t, x)
\end{aligned}
$$

where $x \in \mathbb{R}^{n}, u \in \mathbb{R}$, and the smooth functions $a, b, \sigma$ are unknown. From (24), the time derivative of the sliding surface $\sigma$ can be expressed as

$$
\dot{\sigma}=h(t, x)+g(t, x) u
$$

where $h(t, x)$ and $g(t, x)$ are smooth functions that for some positive constants $\Gamma, K_{M}, K_{m}, U_{M}$, and $q$ the following relations can be held.

$$
\begin{aligned}
|\dot{h}|+U_{M}|\dot{g}| & \leq \Gamma, \quad 0 \leq K_{m} \leq g(t, x) \leq K_{M}, \\
\left|\frac{h}{g}\right| & \leq q U_{M}, \quad 0<q<1
\end{aligned}
$$

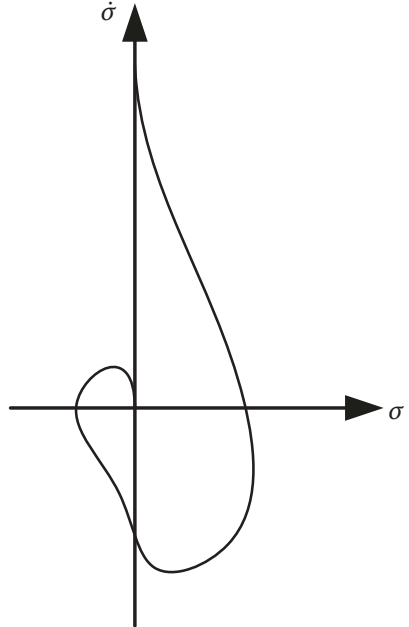

FIgURE 3: Trajectory of the super-twisting controller.

and the input control signal can be defined as

$$
\begin{gathered}
u=-\kappa|\sigma|^{1 / 2} \operatorname{sign}(\sigma)+u_{1}, \\
\dot{u}_{1}= \begin{cases}-u, & |u|>U_{M} \\
-\alpha \operatorname{sign}(\sigma), & |u| \leq U_{M}\end{cases}
\end{gathered}
$$

where $\alpha$ and $\kappa$ should be satisfied with the following conditions:

$$
\begin{aligned}
K_{m} \alpha & >\Gamma \\
& \kappa>\sqrt{\frac{2}{K_{m} \alpha-\Gamma}} \frac{\left(K_{m} \alpha+\Gamma\right) K_{M}(1+q)}{K_{m}^{2}(1-q)}
\end{aligned}
$$

Figure 3 shows the phase portrait in the super-twisting controller.

3.3. Generator Side Converter Controller. As mentioned in the Introduction, to suppress DC-link overvoltage in a grid fault condition and implement LVRT, DC-link voltage is controlled by MSC. In this method, GSC implements MPPT.

The reference value of $\mathrm{d}$-axis current of the generator is zero to reduce the copper loss and to avoid demagnetization of permanent magnets. The q-axis voltage of generator (q-axis input control signal) is produced by DC-link voltage surface.

3.3.1. D-Axis Controller Design. The goal of the d-axis controller is keeping the $\mathrm{d}$-axis current of the generator to zero. Hence, the control object can be expressed by the sliding variable:

$$
\sigma_{d s}=k_{d s} x_{2}
$$

where $k_{d s}$ is a positive constant. By taking the first derivative of $\sigma_{d s}$ and using (18), we have

$$
\dot{\sigma}_{d s}=\frac{k_{d s}}{L_{s}}\left(-R_{s} x_{2}+\frac{p}{2} L_{s} x_{1} x_{3}+V_{d s}\right)
$$


Suppose that the control signal, $V_{d s}$, can be divided into known and unknown terms. Equation (30) can be rewritten as

$$
\dot{\sigma}_{d s}=k_{d s}\left(\frac{p}{2} x_{1} x_{3}+\frac{1}{L_{s}} V_{d s-n}-\frac{R_{s}}{L_{s}} x_{2}+\frac{1}{L_{s}} V_{d s-u n}\right)
$$

where $V_{d s-n}$ is known term of the controller and $V_{d s-u n}$ is the unknown term of the controller. By selecting $V_{d s-n}$ as the following form:

$$
V_{d s-n}=-\frac{p}{2} L_{s} x_{1} x_{3}
$$

and substituting (32) into (31), we have

$$
\dot{\sigma}_{d s}=h_{d s}(.)+g_{d s}(.) V_{d s-u n}
$$

where

$$
\begin{aligned}
& h_{d s}(.)=-\frac{k_{d s} R_{s}}{L_{s}} x_{2}, \\
& g_{d s}(.)=\frac{k_{d s}}{L_{s}} .
\end{aligned}
$$

According to (33), we can use super-twisting sliding mode control. Hence, the unknown term of the d-axis controller can be expressed by

$$
\begin{aligned}
V_{d s-u n} & =-\kappa_{d s}\left|\sigma_{d s}\right|^{1 / 2} \operatorname{sign}\left(\sigma_{d s}\right)+u_{1-d s}, \\
\dot{u}_{1-d s} & = \begin{cases}-V_{d s-u n}, & \left|V_{d s-u n}\right|>U_{M-d s} \\
-\alpha_{d s} \operatorname{sign}\left(\sigma_{d s}\right), & \left|V_{d s-u n}\right| \leq U_{M-d s}\end{cases}
\end{aligned}
$$

where the values of control parameters are given in the Appendix.

3.3.2. Q-Axis Controller Design. The q-axis controller is regulating DC-link voltage in suitable constant value in all conditions such as wind variation condition and grid fault condition that the DC-link voltage may be varied. Also, the relationship between DC-link voltage and the q-axis controller signal is nonlinear. Hence, the control object can be expressed by the sliding surface:

$$
s_{q s}=x_{4}^{r e f}-x_{4}
$$

Let us introduce sliding variable as

$$
\sigma_{q s}=k_{q s 1} s_{q s}+k_{q s 2} \dot{s}_{q s}
$$

where $\dot{s}_{q s}$ is derivative of $s_{q s} . k_{q s 1}$ and $k_{q s 2}$ are positive constants. By dividing $V_{q s}$ known and unknown terms and taking the derivative of $\sigma_{q s}$ and substituting (19) and (20) in it, we have:

$$
\begin{aligned}
V_{q s-n} & =\frac{p}{2} L_{s} x_{1} x_{2}+\frac{3}{2} \frac{p}{2} \psi x_{1} \\
\dot{\sigma}_{q s} & =h_{q s}(.)+g_{q s}(.) V_{q s-u n}
\end{aligned}
$$

where

$$
\begin{aligned}
h_{q s}(.)= & \frac{3 p}{4 C} \psi\left(k_{q s 1}-\frac{k_{q s 2}}{L_{s}} R_{s}\right) x_{1} x_{2} \\
& +\frac{k_{q s 1}}{C}\left(P_{\text {loss }}+P_{\text {grid }}\right) \\
& +\frac{k_{q s 2}}{C} \frac{d}{d t}\left(P_{\text {loss }}+P_{\text {grid }}\right), \\
g_{q s}(.)= & \frac{3 p k_{q s 2}}{4 C L_{s}} \psi x_{1} .
\end{aligned}
$$

According to (39), we can use super-twisting sliding mode control. Hence, the unknown term of q-axis controller can be expressed by

$$
\begin{aligned}
V_{q s-u n}=-\kappa_{q s}\left|\sigma_{q s}\right|^{1 / 2} \operatorname{sign}\left(\sigma_{q s}\right)+u_{1-q s}, \\
\dot{u}_{1-q s}= \begin{cases}-V_{q s-u n}, & \left|V_{q s-u n}\right|>U_{M-q s} \\
-\alpha_{q s} \operatorname{sign}\left(\sigma_{q s}\right), & \left|V_{q s-u n}\right| \leq U_{M-q s}\end{cases}
\end{aligned}
$$

As a result, q-axis control law becomes

$$
V_{q s}=V_{q s-n}+V_{q s-u n}
$$

3.4. Grid Side Converter Controller. The GSC has two main tasks: first, MPPT control of wind turbine, second, reactive power supporting the grid in different situations such as grid voltage drop. The d-axis controller performs MPPT control and q-axis controller supports reactive power.

3.4.1. D-Axis Controller Design. As mentioned above, MPPT is implemented by the d-axis controller of GSC. There are several approaches to implement MPPT that among them optimal power control (OPC) can be applied to PMSG-based wind turbines [25]. In this design, the OPC method is used.

Considering (4) and (5) and replacing the optimal value of $C_{p-\text { max }}$ and $\lambda_{o p t}$ the wind turbine mechanical torque can be given as a function of $\omega_{m}$, as follows:

$$
T_{m-o p t}=k_{o p t} \omega_{m}^{2}
$$

where $k_{o p t}=0.5 \rho \pi r^{5}\left(C_{p-\max } / \lambda_{o p t}^{3}\right)$.

The optimal mechanical power of the turbine can be obtained by multiplying both sides of (43) by $\omega_{m}$. Thus

$$
P_{m-o p t}=k_{o p t} \omega_{m}^{3}
$$

The PCC power reference can be obtained by subtracting the losses of optimal mechanical wind turbine power as

$$
P_{\text {PCC-opt }}=k_{\text {opt }} \omega_{m}^{3}-B \omega_{m}^{2}-P_{\text {loss }}-P_{\text {loss-filter }}
$$

where $P_{\text {loss-filter }}$ is the RL filter loss. From (15) and (45), the $\mathrm{d}$-axis reference current is obtained as

$$
i_{d f}^{r e f}=\frac{2}{3} \frac{P_{P C C-o p t}}{V_{d f}}
$$


It should be noted that, in voltage drop conditions, Danish grid code enforces wind power plants to inject reactive current to PCC according to Figure 1 . Hence, the daxis current should be limited to produce reactive current by the q-axis controller because the current capacity of power electronic converter is limited. The value and upper limit of $\mathrm{d}-\mathrm{q}$ axis currents in different conditions becomes

$$
\begin{aligned}
& i_{d f-u l}=I_{m}, \\
& i_{q f-u l}=\sqrt{I_{m}^{2}-i_{d f-p u}^{2}}, \\
& \text { if } 0.9<V_{d f-p u} \leq 1 \\
& i_{d f-u l}=\sqrt{I_{m}^{2}-i_{q f-p u}^{2}}, \\
& i_{q f-p u}=-2.5 V_{d f-p u}+2.25 \text {, } \\
& \text { if } 0.5<V_{d f-p u} \leq 0.9 \\
& i_{d f-u l}=0, \\
& i_{q f-u l}=I_{m}, \\
& \text { if } 0.2<V_{d f-p u} \leq 0.5
\end{aligned}
$$

where $I_{m}, i_{d f-u l}$, and $i_{q f-u l}$ are the per unit of rated current of the converter, the per unit of the upper limit of $d$-axis current, and the per unit of the upper limit of q-axis current, respectively. $V_{d f-p u}, i_{d f-p u}$, and $i_{q f-p u}$ are the per unit of daxis voltage in PCC, the per unit of $\mathrm{d}$-axis current, and the per unit of q-axis current, respectively. Now, by calculating the daxis current from (46) and applying (47), the d-axis controller can be designed.

The control objective can be expressed by the sliding variable:

$$
\sigma_{d f}=k_{d f}\left(x_{5}-x_{5}^{r e f}\right)
$$

where $k_{d f}$ is a positive constant. By taking the first derivative of $\sigma_{d f}$ and using (21), we have

$$
\begin{aligned}
& \dot{\sigma}_{d f} \\
& \quad=k_{d f}\left(-\frac{R_{f}}{L_{f}} x_{5}+\omega_{f} x_{6}+\frac{1}{L_{f}} e_{d f}-\frac{1}{L_{f}} V_{d f}-\dot{x}_{5}^{r e f}\right)
\end{aligned}
$$

Suppose that $e_{d f}$ can be divided into known and unknown terms. Equation (49) can be rewritten as

$$
\begin{aligned}
\dot{\sigma}_{d f} & =k_{d f}\left(-\frac{1}{L_{f}} V_{d f}+\omega_{f} x_{6}+\frac{1}{L_{f}} e_{d s-n}-\frac{R_{f}}{L_{f}} x_{5}\right. \\
& \left.-\dot{x}_{5}^{r e f}+\frac{1}{L_{f}} e_{d s-u n}\right)
\end{aligned}
$$

where $e_{d f-n}$ is known term of the controller and $e_{d f-u n}$ is an unknown term of the controller. By selecting $e_{d f-n}$ as the following form

$$
e_{d f-n}=V_{d f}-\omega_{f} L_{f} x_{6}
$$

and substituting (51) into (50), we have

$$
\dot{\sigma}_{d f}=h_{d f}(.)+g_{d f}(.) e_{d f-u n}
$$

where $h_{d f}()=.-k_{d f}\left(\left(R_{f} / L_{f}\right) x_{5}+\dot{x}_{5}^{r e f}\right), g_{d f}()=.k_{d f} / L_{f}$.

According to (52), we can use super-twisting sliding mode control. Hence, the unknown terms of the d-axis controller can be expressed by

$$
\begin{aligned}
& e_{d f-u n}=-\kappa_{d f}\left|\sigma_{d f}\right|^{1 / 2} \operatorname{sign}\left(\sigma_{d f}\right)+u_{1-d f}, \\
& \dot{u}_{1-d f}= \begin{cases}-e_{d f-u n}, & \left|e_{d f-u n}\right|>U_{M-d f} \\
-\alpha_{d f} \operatorname{sign}\left(\sigma_{d f}\right), & \left|e_{d f-u n}\right| \leq U_{M-d f}\end{cases}
\end{aligned}
$$

As a result, the q-axis control law becomes

$$
e_{d f}=e_{d f-n}+e_{d f-u n}
$$

3.4.2. Q-Axis Controller Design. The main task of the q-axis controller is reactive power supporting the grid in different conditions. The q-axis current reference can be produced by reactive power demand of PCC by (16) in normal condition and by (47) in the grid voltage drop conditions. The design procedure is similar to the d-axis controller design. Hence, to avoid repeating, it is written only sliding variable and q-axis control low equation.

$$
\begin{aligned}
\sigma_{q f} & =k_{q f}\left(x_{6}-x_{6}^{r e f}\right) \\
e_{q f-n} & =\omega_{f} L_{f} x_{5} \\
e_{q f-u n} & =-\kappa_{q f}\left|\sigma_{q f}\right|^{1 / 2} \operatorname{sign}\left(\sigma_{q f}\right)+u_{1-q f}, \\
\dot{u}_{1-q f} & = \begin{cases}-e_{q f-u n}, & \left|e_{q f-u n}\right|>U_{M-q f} \\
-\alpha_{q f} \operatorname{sign}\left(\sigma_{q f}\right), & \left|e_{q f-u n}\right| \leq U_{M-q f}\end{cases}
\end{aligned}
$$

As a result, $\mathrm{q}$-axis control law becomes

$$
e_{q f}=e_{q f-n}+e_{q f-u n}
$$

\section{Simulation Results}

To evaluate the performances of designed super-twisting sliding mode control in the PMSG-based wind turbines, the several simulations have been carried out on the MAT$\mathrm{LAB} /$ Simulink software. Then this method is compared with the PI controller [8] and FOSMC [13]. The parameters of a 1.5 MW PMSG-based wind turbine and grid characteristics are given in Table 1.

4.1. Operation with Symmetrical Grid Faults. As mentioned above, the relationship between the DC-link voltage and the generator $q$-axis input control signal is nonlinear. In controlling and regulating the DC-link voltage at a constant value in all conditions such as grid fault situation, three controllers (PI, FOSMC, and STSMC) are compared. To evaluate the performances of these controllers, symmetrical 


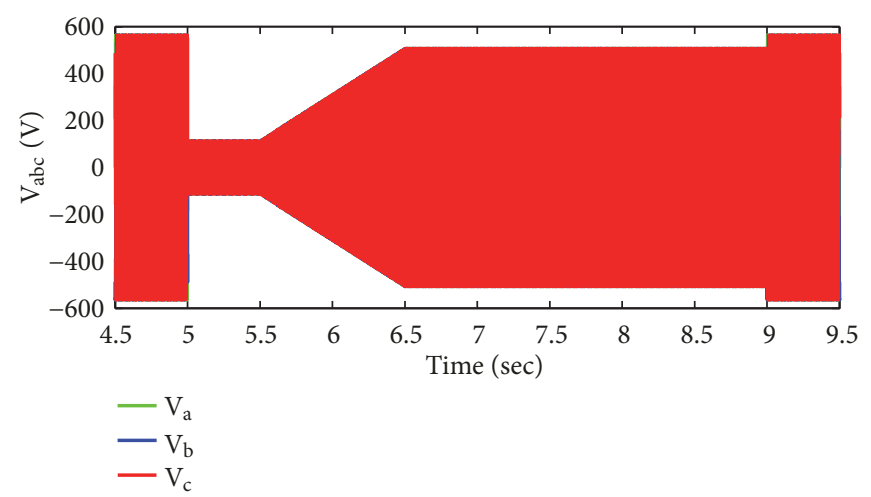

FIGURE 4: Grid voltage profile during a three-phase symmetrical voltage drop.

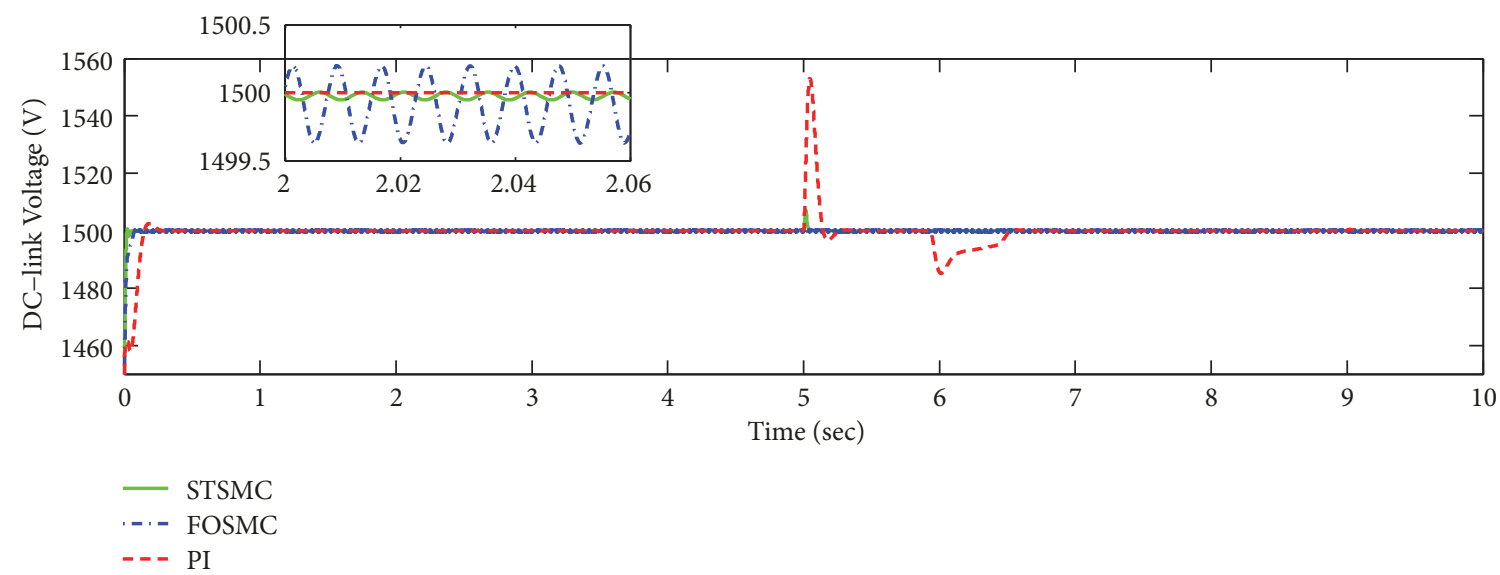

(a)

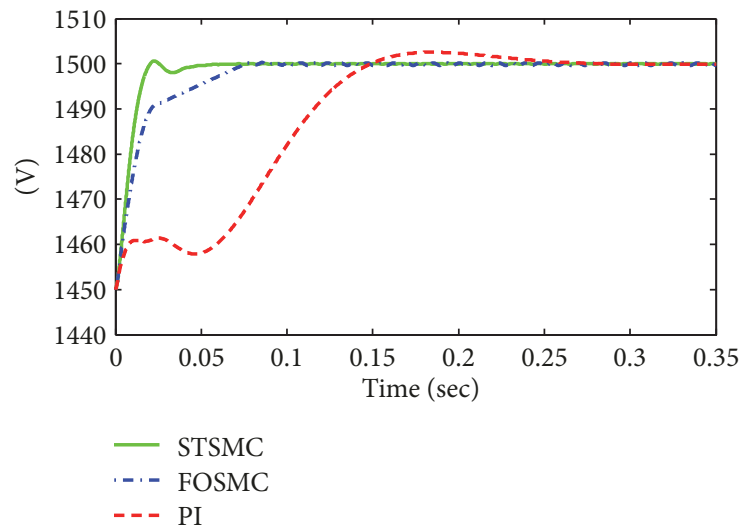

(b)

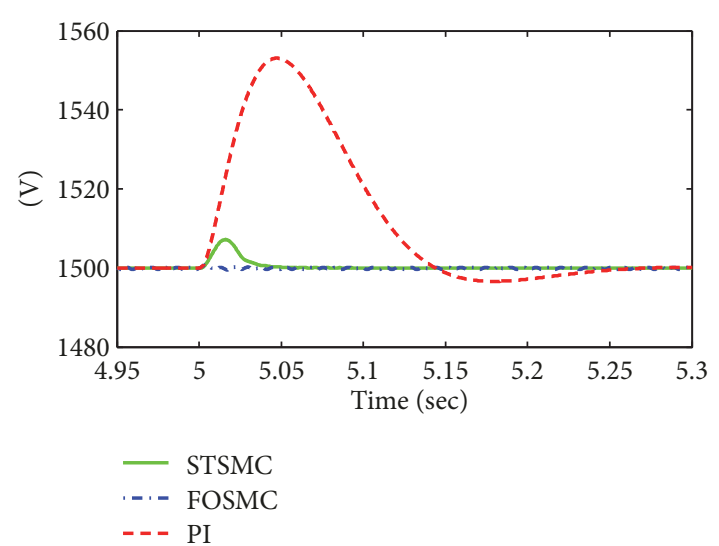

(c)

FIGURE 5: The DC-link voltage variation (a) with PI, FOSMC, and STSMC in the grid fault condition, (b) in starting time, and (c) in beginning time of grid voltage drop.

voltage drop similar to the Danish grid code (Figure 1) at $t=5 \mathrm{~s}$ is applied as shown in Figure 4.

Figure 5 shows the DC-link voltage variation with three controllers. As shown in Figure 5, the STSMC has the best performances in DC-link voltage control in both starting time and grid voltage drop. According to Figure 5(a), the FOSMC has higher chattering in all time. In addition, STSMC has the fast starting time (Figure 5(b)). Furthermore, in the
PI controller, the peak of the DC-link voltage reaches $1556 \mathrm{~V}$ while in STSMC, it is less than $1510 \mathrm{~V}$ (Figure 5(c)).

Figure 6 shows the q-axis current of the generator. This component of current controls the DC-link voltage. As shown in Figures 6(a) and 6(b), the STSMC has fast response in the grid voltage drop. Hence, this subject can reduce the DC-link overvoltage. The FOSMC has chattering and it can fatigue the DC-link capacitor. 


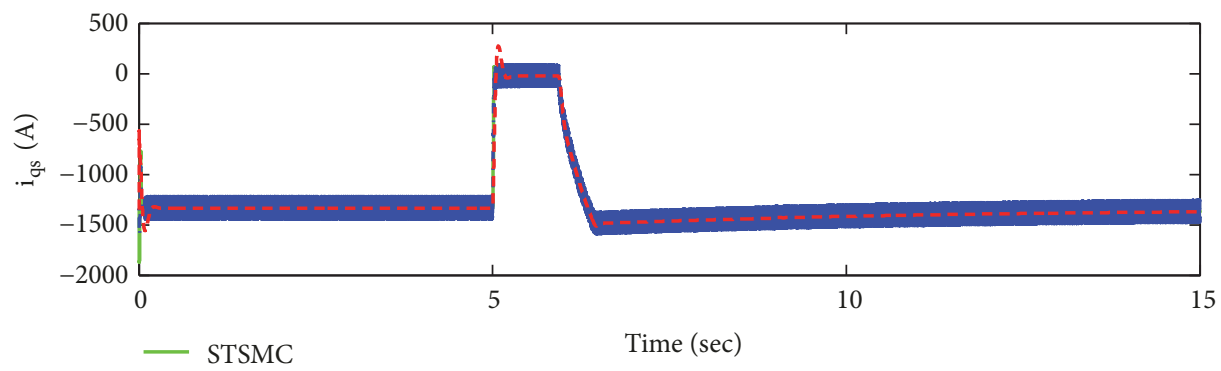

- - FOSMC

-.- PI

(a)

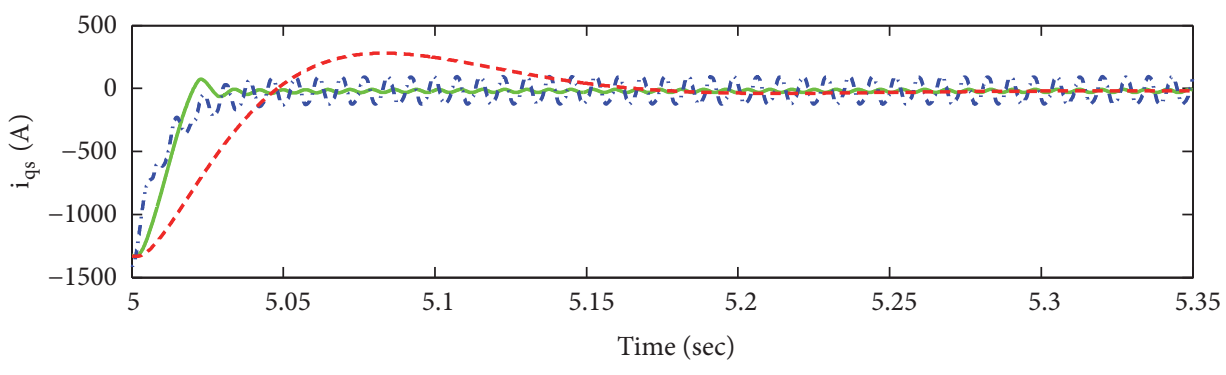

STSMC

-. FOSMC

-.- PI

(b)

FIgURE 6: The q-axis current of the generator (a) with PI, FOSMC, and STSMC in the grid fault condition, (b) in beginning time of grid voltage drop.

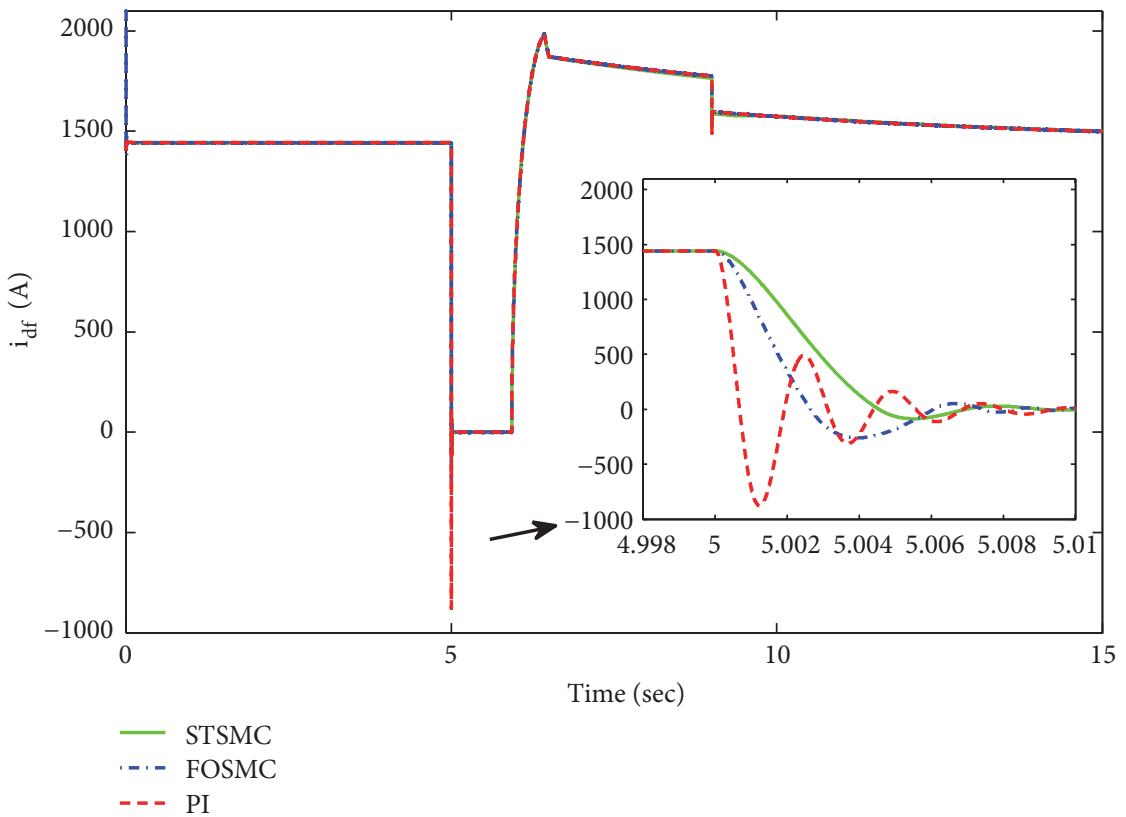

FIgURE 7: The d-axis current of the GSC with PI, FOSMC, and STSMC.

The d-axis current of the GSC is shown in Figure 7. According to Figure 7, PI controller has worst performance in the grid fault condition.

In Figure 8, q-axis current of the GSC is shown. Although all of the controllers satisfy the injecting reactive current according to the grid code, similar to Figure 7, the PI controller does not have good performance.

As mentioned above, one of the main drawbacks of FOSMC is chattering especially in the input of controllers that results in chattering in systems variables. Figure 9 shows the 


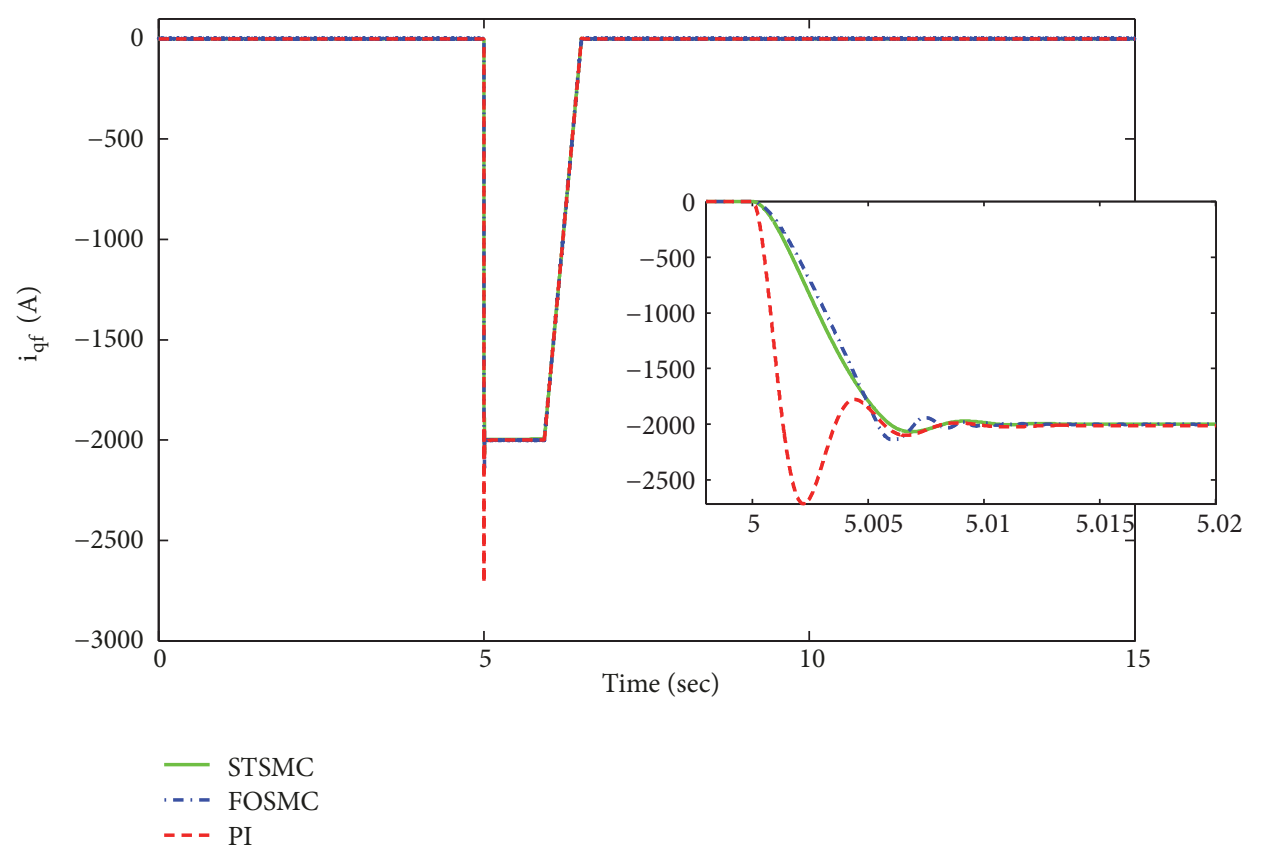

Figure 8: The q-axis current of the GSC with PI, FOSMC, and STSMC.

TABLE 1: The parameters of a 1.5 MW PMSG-based wind turbine and grid characteristics.

\begin{tabular}{lccc}
\hline \multicolumn{2}{c}{ Turbine parameters } & \multicolumn{2}{c}{ PMSG and Grid parameters } \\
Parameter & Value & Parameter & Value \\
\hline$r[\mathrm{~m}]$ & 36.6 & $R_{s}[\mathrm{~m} \Omega]$ & 3.174 \\
$\rho\left[\mathrm{kg} / \mathrm{m}^{3}\right]$ & 1.225 & $L_{s}[\mathrm{mH}]$ & 3.07 \\
$J_{\text {eq }}\left[\mathrm{kg} \cdot \mathrm{m}^{2}\right]$ & 4800000 & $C[F]$ & 0.23 \\
$B_{e q}[\mathrm{~N} \cdot \mathrm{m} \cdot \mathrm{s} / \mathrm{rad}]$ & 200 & $\psi[w b]$ & 7.017 \\
$\lambda_{\text {opt }}$ & 8.1 & $p$ & 80 \\
$C_{p-\max }$ & 0.48 & $V_{d c}[\mathrm{~V}]$ & 1500 \\
\hline
\end{tabular}

input control signals to the MSC and GSC in the FOSMC. As shown in Figure 9, the amplitude of chattering in controller signals is extremely high. To overcome this drawback, the STSMC is suitable solution. Figure 10 shows input control signals to the MSC and GSC in the super-twisting controller. As it is seen, the chattering in the input control signals is reduced.

The phase portraits corresponding to the reaching phase of the $d-q$ axis sliding variables of the generator side and grid side controllers in the STSMC are depicted in Figure 11. These plots (Figures 11(a)-11(e)) show the features illustrated by super-twisting controllers during the system convergence toward $\sigma=\dot{\sigma}=0$.

To show the compliance of the grid code requirements in reactive current injection by the designed system, the injected reactive current versus grid voltage drop is shown in Figure 12. As shown in Figure 9, the designed controller injects reactive current similar to Figure 1(b).
TABLE 2: The amplitude and frequency of wind speed components [18].

\begin{tabular}{lccccccc}
\hline$i$ & 1 & 2 & 3 & 4 & 5 & 6 & 7 \\
\hline$A_{i}[\mathrm{~m} / \mathrm{s}]$ & 0.7 & 0.1 & 0.7 & 0.5 & 0.4 & 0.3 & 0.2 \\
$\omega_{i}[\mathrm{rad} / \mathrm{s}]$ & $0.02 \pi$ & 0.3 & 1 & $\pi$ & 10 & $10 \pi$ & 50 \\
\hline
\end{tabular}

4.2. Operation with Asymmetrical Grid Fault. To evaluate the performance of proposed controller in asymmetrical voltage drop, a single-phase voltage drop is simulated in phase A. Figure 13 shows the PCC voltage in single-phase voltage drop.

Figure 14 shows DC-link voltage variation in single-phase voltage drop. As shown, there is low amplitude fluctuation in the DC-link voltage in asymmetrical voltage drop. However, the STSMC has good performance in this condition.

4.3. Operation in Normal Condition. To emulate the performance of the super-twisting controllers in normal condition, a wind velocity profile is defined as expressed in [22]:

$$
v_{w}(t)=10+\sum A_{i} \sin \left(\omega_{i} t\right)
$$

The amplitude and frequency of wind velocity components are given in Table 2 . The resultant wind velocity profile is as shown in Figure 15(a). Figure 15(b) shows wind turbine power $\left(P_{m}\right)$ and injected active power $\left(P_{\text {grid }}\right)$ to PCC. Figure 15(c) shows the power coefficient of the wind turbine. The average of $C_{p}$ is 0.4493 from $t=5 s$ to $t=40 \mathrm{~s}$. Of course, when the wind speed increases from $12 \mathrm{~m} / \mathrm{s}$ the turbine power reaches the nominal value. Hence, the pitch angle controller will be active to set turbine power in nominal power as shown in Figure $15(d)$. As a result, $C_{p}$ is slightly less than 0.48 . It is 


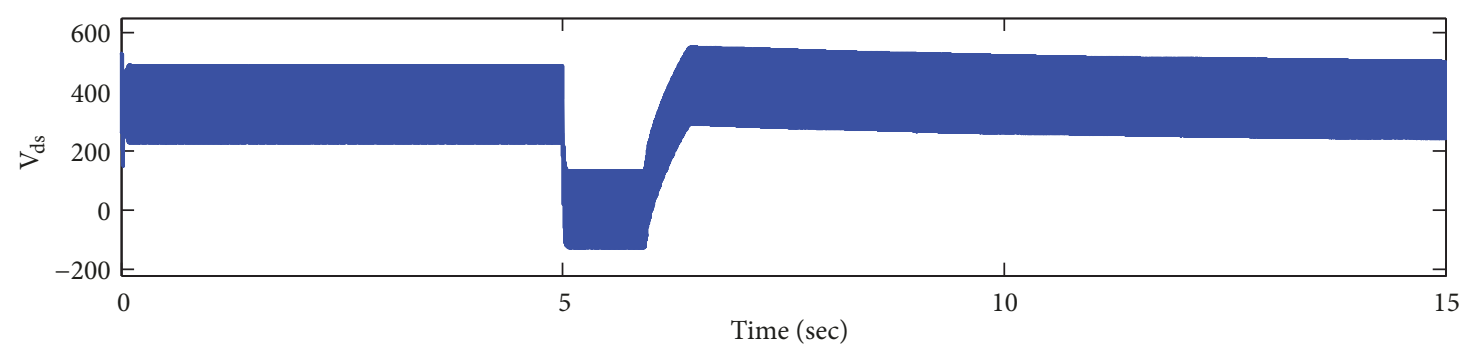

(a)

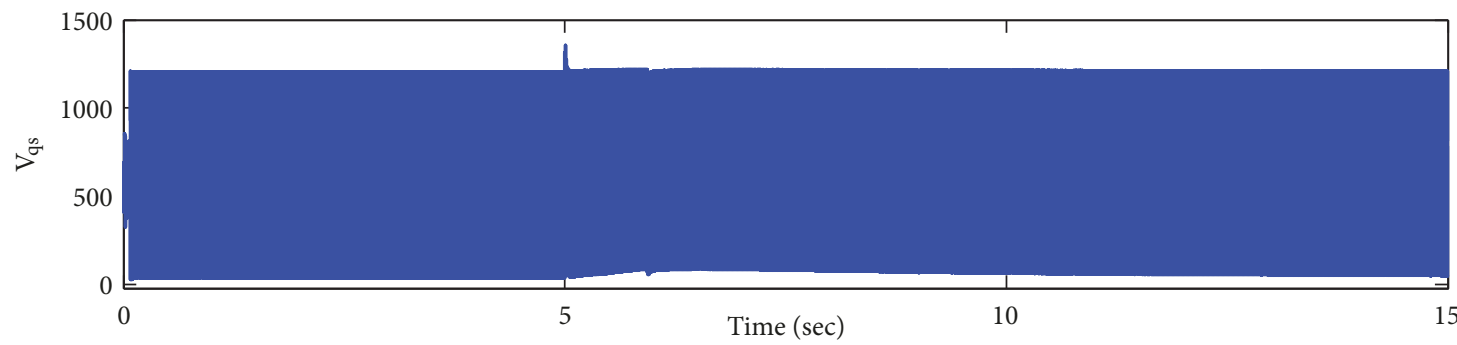

(b)

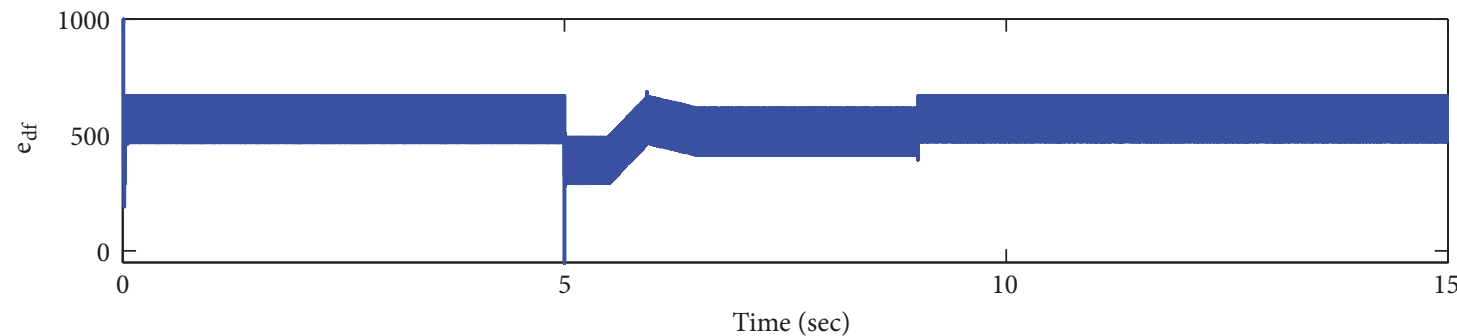

(c)

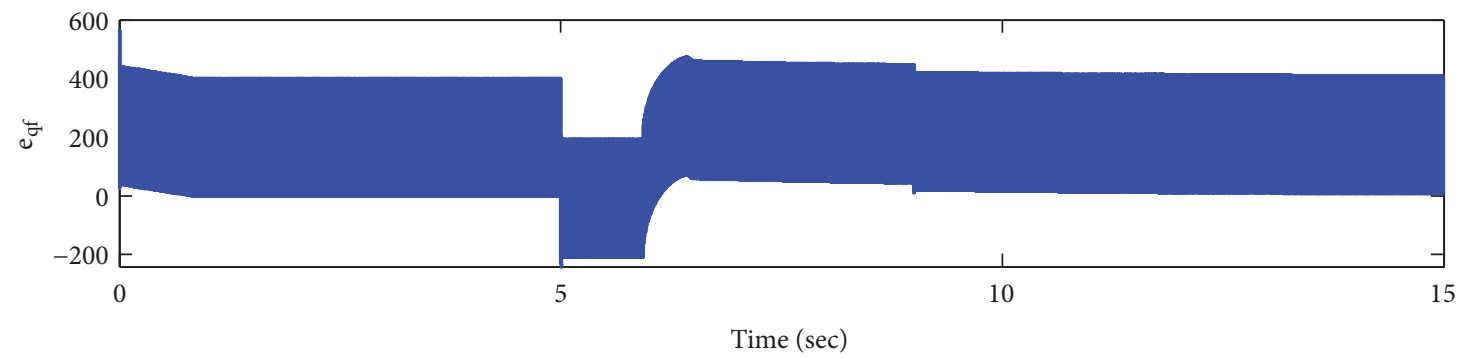

(d)

FIGURE 9: The d-q axis input controller signals for (a) and (b) MSC, (c) and (d) GSC, in FOSMC.

clear that with the STSMC, also, MPPT is perfectly achieved. As shown in Figure 15(e), the DC-link voltage is fixed in $1500 \mathrm{~V}$. This shows the robust DC-link voltage against wind fluctuations.

\section{Conclusions}

This paper presents a super-twisting sliding mode control for gearless PMSG-based variable speed wind turbines. First, the mathematical models of the wind turbine, PMSG, DC-link, and grid are represented. Then the super-twisting controllers are designed for generator and grid side converters. The proposed controller is compared with the proportional-integral
(PI) controller and first-order sliding mode controller (FOSMC). By applying the proposed controller, the DClink overvoltage is significantly reduced rather than the PI controller. Furthermore, chattering is reduced in input controller signals and DC-link voltage. Also, the reactive current injection is done according to modern grid codes. In order to evaluate the performance of the super-twisting controllers in unbalanced voltage drop, it has simulated a single-phase voltage drop. Furthermore, designed controller can greatly do the MPPT and regulates the DC-link voltage in reference value in normal condition. The robustness and effectiveness of the designed super-twisting controllers in different conditions are confirmed by simulation results. 


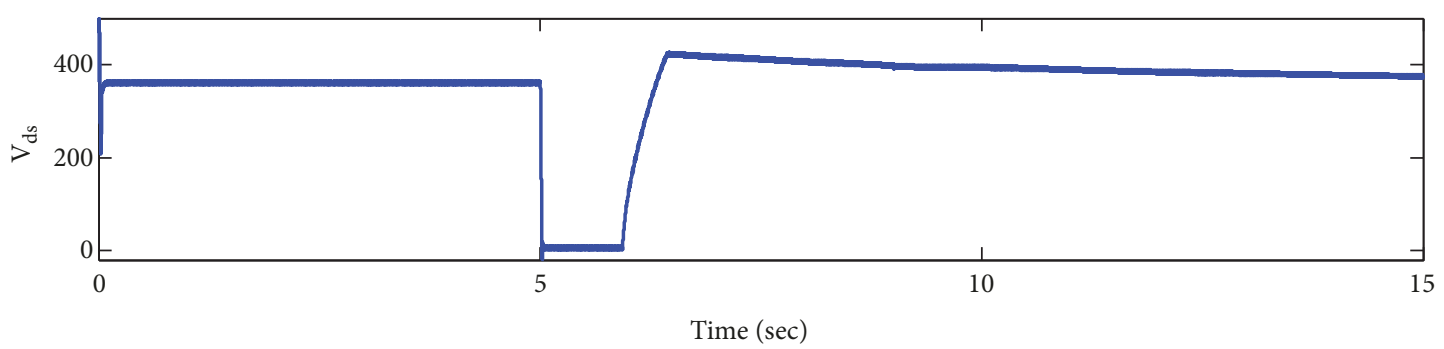

(a)

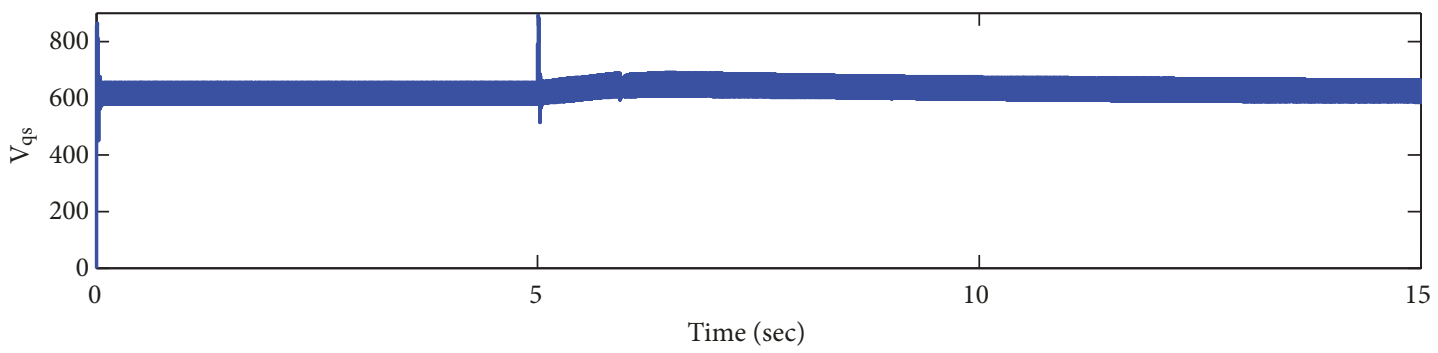

(b)

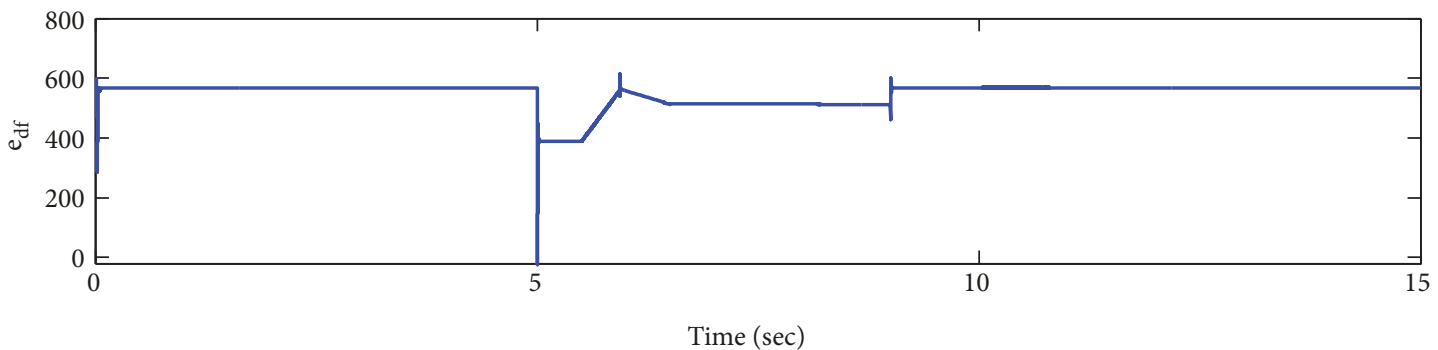

(c)

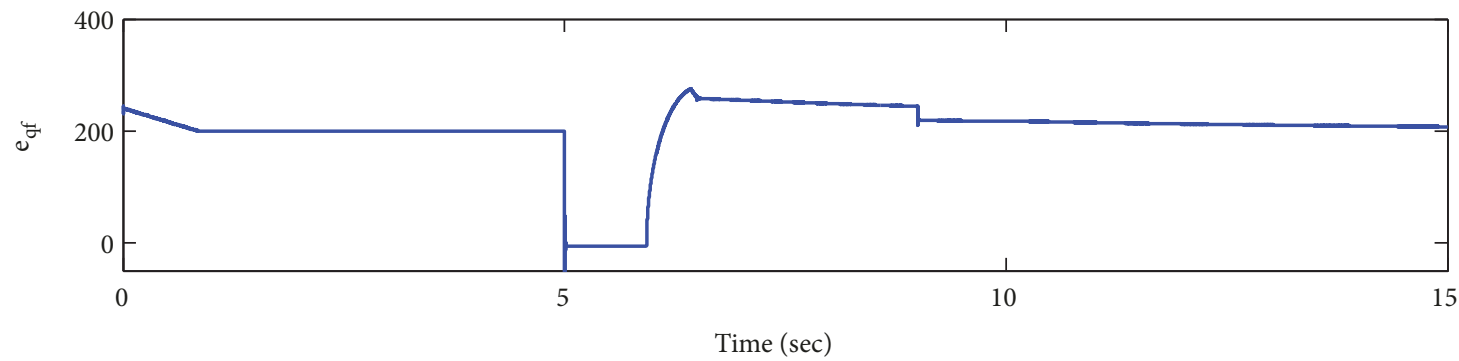

(d)

FIGURE 10: The d-q axis input controller signals for (a) and (b) MSC, (c) and (d) GSC, in STSMC.

Appendix

$$
\begin{aligned}
\kappa_{d s} & =0.55, \\
\alpha_{d s} & =15, \\
U_{M-d s} & =0.5, \\
k_{d s} & =10, \\
\kappa_{q s} & =0.037, \\
\alpha_{q s} & =2500, \\
U_{M-q s} & =11,
\end{aligned}
$$

$$
\begin{aligned}
k_{q s 1} & =3600, \\
k_{q s 2} & =29, \\
\kappa_{d f} & =0.2, \\
\alpha_{d f} & =200, \\
U_{M-d f} & =5, \\
k_{d f} & =1000, \\
\kappa_{q f} & =4, \\
\alpha_{q f} & =100,
\end{aligned}
$$




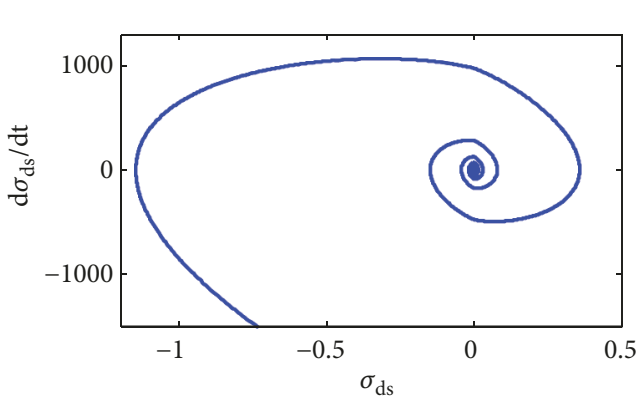

(a)

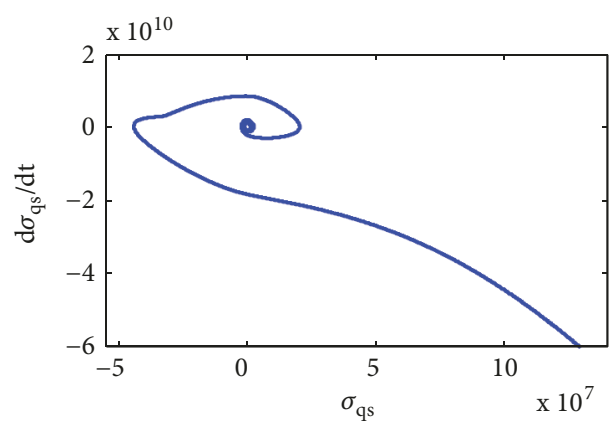

(c)

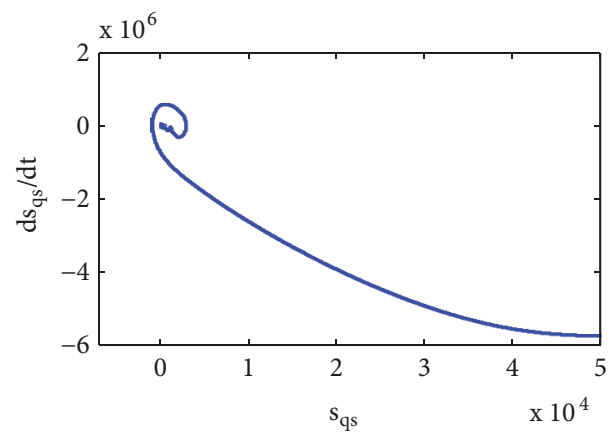

(b)

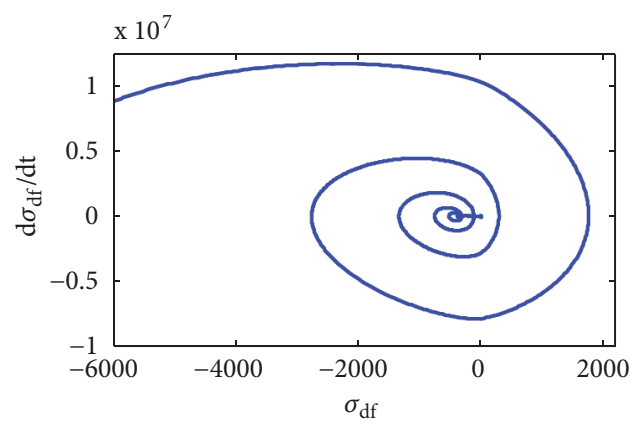

(d)

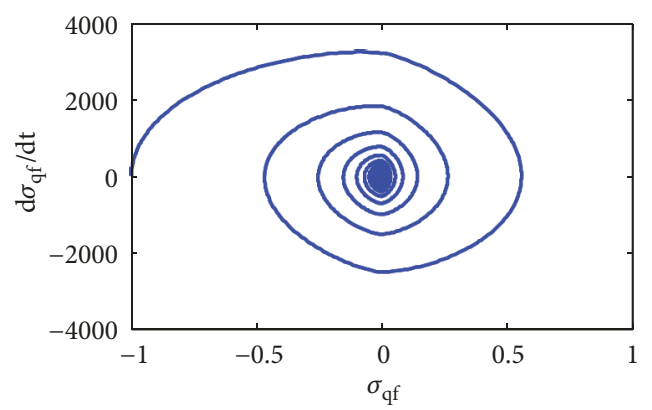

(e)

FIGURE 11: Phase portraits of the sliding variables.

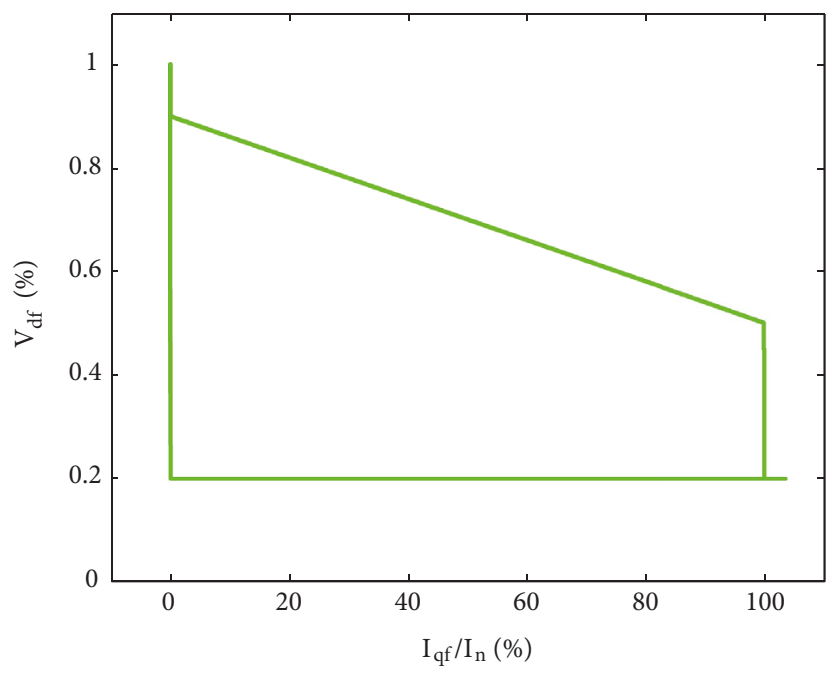

FIGURE 12: The percent of injected reactive current to the grid versus the voltage drop of PCC. 


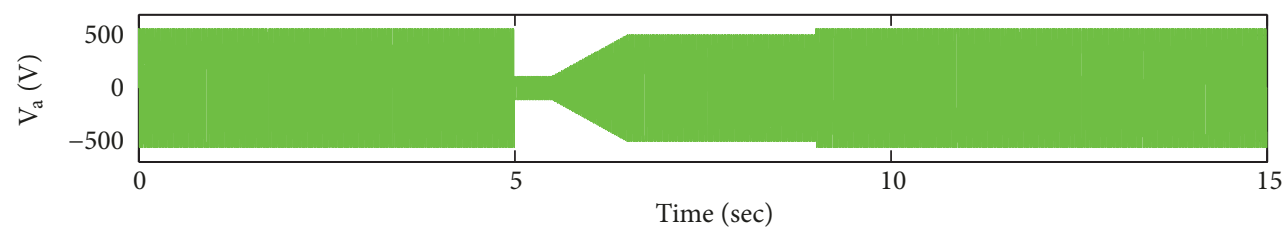

(a)

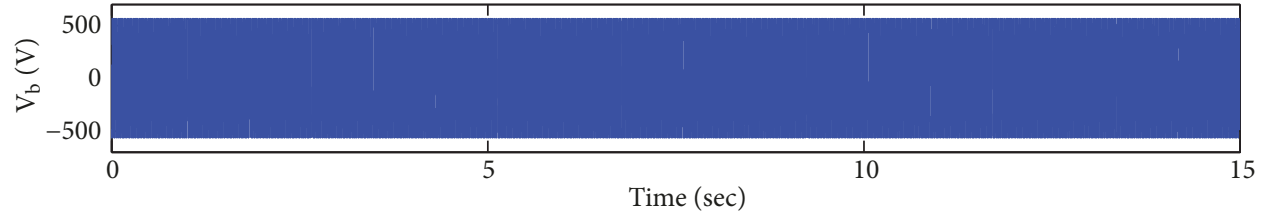

(b)

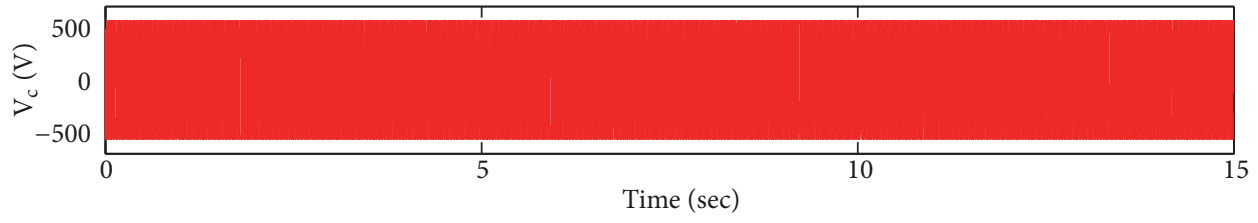

(c)

FIGURE 13: The grid voltage profile during a single-phase voltage drop, (a) phase A, (b) phase B, and (c) phase C.

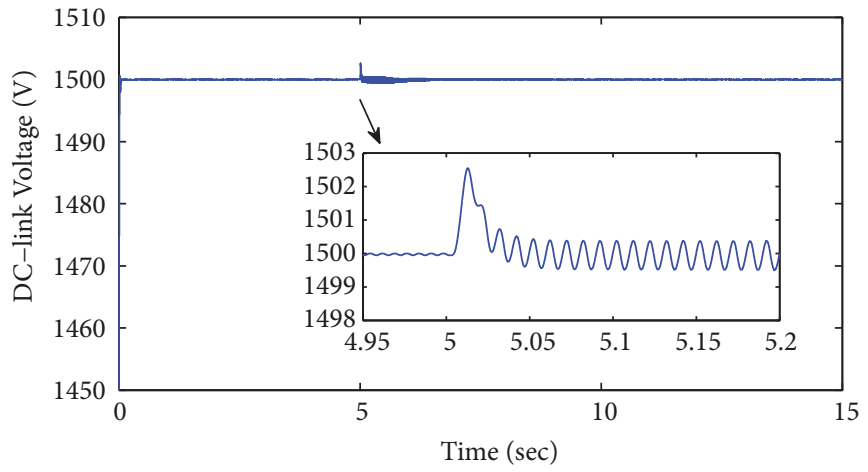

FIGURE 14: The DC-link voltage profile during a single-phase voltage drop.

$$
\begin{gathered}
U_{M-q f}=5, \\
k_{q f}=2 .
\end{gathered}
$$

\section{Nomenclature}

\section{Symbols}

$\begin{array}{ll}\rho: & \text { Air density }\left(\mathrm{kg} / \mathrm{m}^{3}\right) \\ r: & \text { Radius of blade }(\mathrm{m}) \\ \beta: & \text { Pitch angle }\left(^{\circ}\right) \\ \lambda: & \text { Tip-speed ratio } \\ C_{p}(\lambda, \beta): & \text { Power coefficient } \\ v_{w}: & \text { Wind speed }(\mathrm{m} / \mathrm{s}) \\ J_{e q}: & \text { Total equivalent inertia }\left(\mathrm{kg} \mathrm{m^{2 }}\right) \\ B_{e q}: & \text { Viscous friction coefficient }(\mathrm{N} \mathrm{m} \mathrm{s/rad}) \\ p: & \text { Number of poles } \\ \omega_{m}: & \text { Shaft speed }(\mathrm{rad} / \mathrm{s})\end{array}$

$\omega_{e}:$ Electrical angular velocity $(\mathrm{rad} / \mathrm{s})$

$R:$ Resistance $(\Omega)$

$L:$ Inductance $(H)$

$C$ : DC-link capacitance $(F)$

$\mathrm{k}$ : Positive gain

$e$ : Grid side inverter voltage

$V$ : Voltage $(V)$

$i$ : Current $(A)$

$\psi:$ Flux $(w b)$

\section{Subscripts}

d, q: Direct and quadrature components

s: Stator of machine

$f$ : $\quad$ Grid side

dc: DC-link

Superscripts

ref: Reference. 


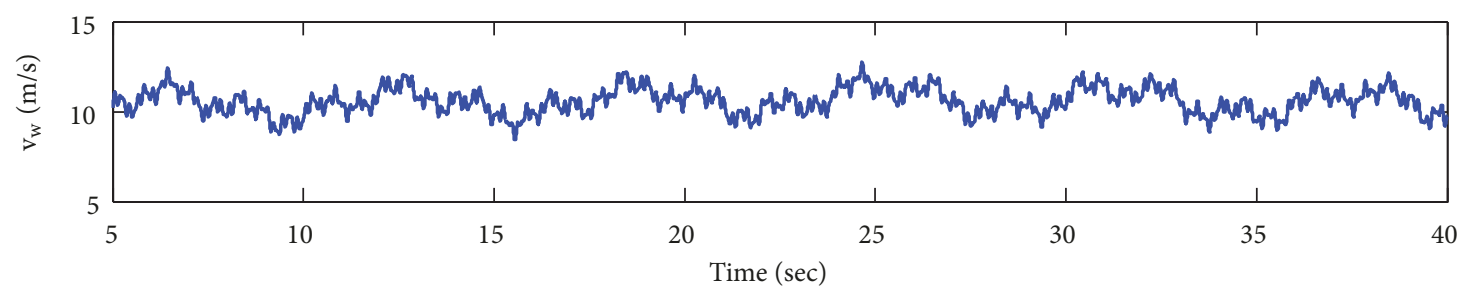

(a)

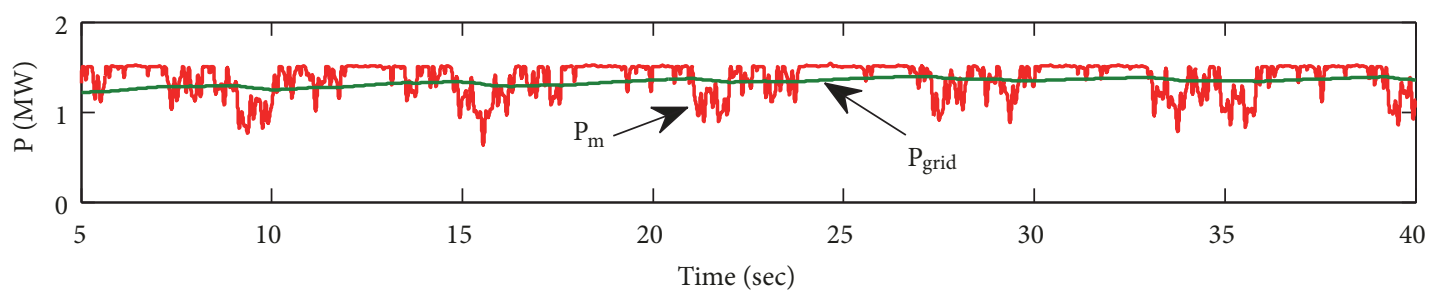

(b)

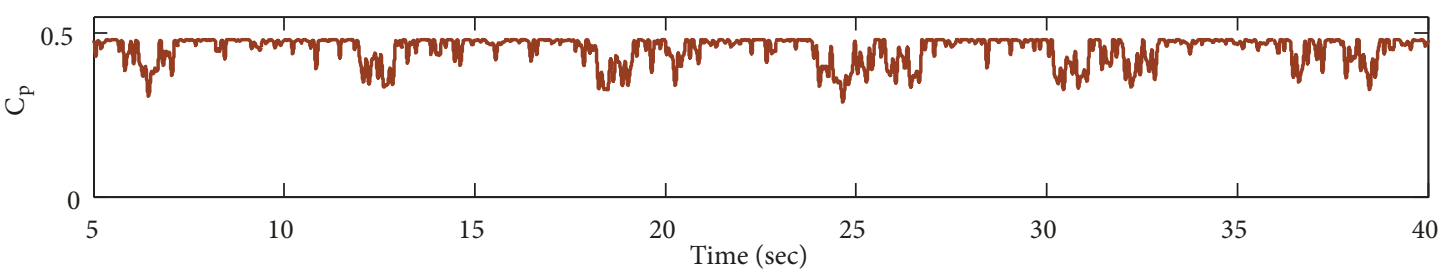

(c)

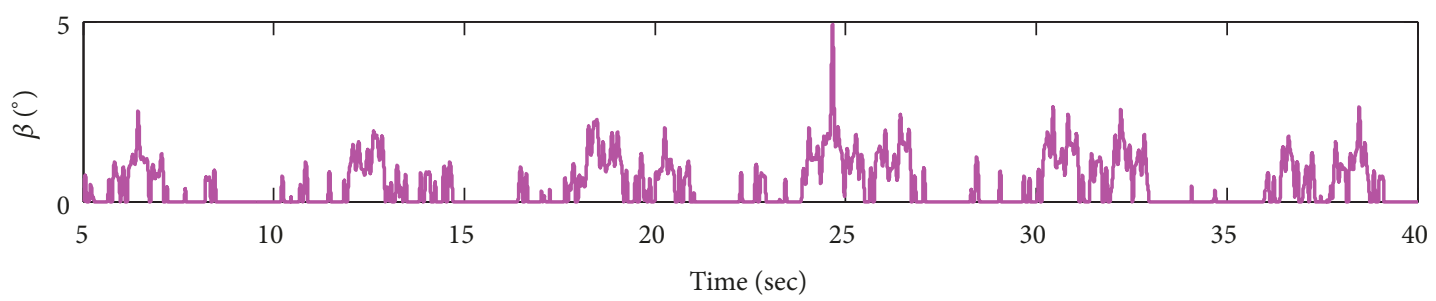

(d)

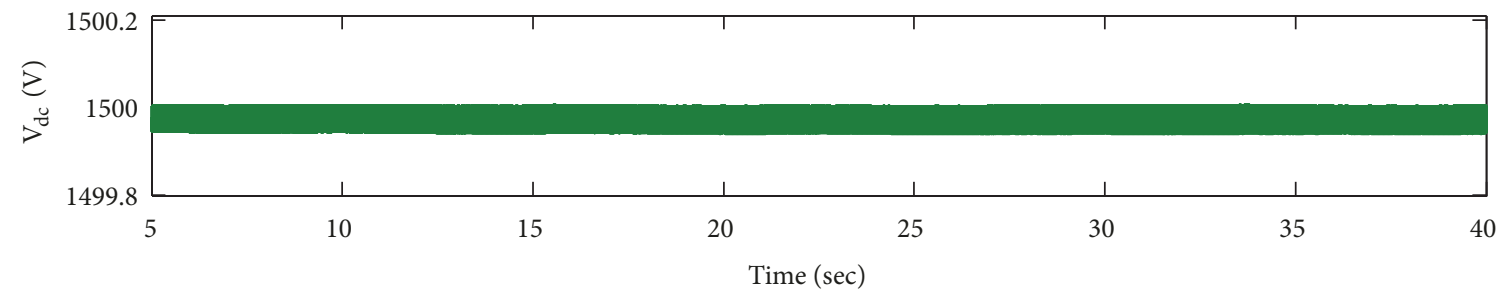

(e)

FIGURE 15: (a) wind speed profile, (b) wind turbine power $\left(P_{m}\right)$, injected active power $\left(P_{\text {grid }}\right)$ to PCC, (c) power coefficient of the wind turbine, (d) pitch angle, and (e) DC-link voltage, in STSMC.

\section{Data Availability}

The MATLAB files data used to support the findings of this study are available from the corresponding author upon request.

\section{Conflicts of Interest}

The authors declare that they have no conflict of interest.

\section{References}

[1] P. Michalak and J. Zimny, "Wind energy development in the world, Europe and Poland from 1995 to 2009; Current status and future perspectives," Renewable \& Sustainable Energy Reviews, vol. 15, no. 5, pp. 2330-2341, 2011.

[2] J. Chen, W. Yao, C. Zhang, Y. Ren, and L. Jiang, "Design of robust MPPT controller for grid-connected PMSG-Based wind turbine via perturbation observation based nonlinear adaptive 
control," Journal of Renewable Energy, vol. 134, pp. 478-495, 2019.

[3] F. Blaabjerg and K. Ma, "Wind energy systems," Proceedings of the IEEE, vol. 105, no. 11, pp. 2116-2131, 2017.

[4] F. Blaabjerg, Y. Yang, D. Yang, and X. Wang, "Distributed powergeneration systems and protection," Proceedings of the IEEE, vol. 105, no. 7, pp. 1311-1331, 2017.

[5] C.-N. Wang, W.-C. Lin, and X.-K. Le, "Modelling of a PMSG wind turbine with autonomous control," Mathematical Problems in Engineering, vol. 2014, Article ID 856173, 9 pages, 2014.

[6] S. Li, T. A. Haskew, R. P. Swatloski, and W. Gathings, "Optimal and direct-current vector control of direct-driven PMSG wind turbines," IEEE Transactions on Power Electronics, vol. 27, no. 5, pp. 2335-2337, 2012.

[7] P. Xing, L. Fu, G. Wang, Y. Wang, and Y. Zhang, "A compositive control method of low-voltage ride through for PMSG-based wind turbine generator system," IET Generation, Transmission \& Distribution, vol. 12, no. 1, pp. 117-125, 2017.

[8] M. Nasiri, J. Milimonfared, and S. H. Fathi, "A review of lowvoltage ride-through enhancement methods for permanent magnet synchronous generator based wind turbines," Renewable \& Sustainable Energy Reviews, vol. 47, pp. 399-415, 2015.

[9] A. D. Hansen and G. Michalke, "Multi-pole permanent magnet synchronous generator wind turbines' grid support capability in uninterrupted operation during grid faults," IET Renewable Power Generation, vol. 3, no. 3, pp. 333-348, 2009.

[10] M. Nasiri and R. Mohammadi, "Peak current limitation for grid side inverter by limited active power in PMSG-based wind turbines during different grid faults," IEEE Transactions on Sustainable Energy, vol. 8, no. 1, pp. 3-12, 2017.

[11] K.-H. Kim, Y.-C. Jeung, D.-C. Lee, and H.-G. Kim, "LVRT scheme of PMSG wind power systems based on feedback linearization," IEEE Transactions on Power Electronics, vol. 27, no. 5, pp. 2376-2384, 2012.

[12] M. Nasiri, J. Milimonfared, and S. Fathi, "Efficient lowvoltage ride-through nonlinear backstepping control strategy for PMSG-based wind turbine during the grid faults," Journal of Operation and Automation in Power Engineering, vol. 6, no. 2, pp. 218-228, 2018.

[13] M. Nasiri, J. Milimonfared, and S. H. Fathi, "Robust control of PMSG-based wind turbine under grid fault conditions," Indian Journal of Science and Technology, vol. 8, no. 13, 2015.

[14] H. Sun, Y. Han, and L. Zhang, "Maximum wind power tracking of doubly fed wind turbine system based on adaptive gain second-order sliding mode," Journal of Control Science and Engineering, vol. 2018, Article ID 5342971, 11 pages, 2018.

[15] M. Benbouzid, B. Beltran, Y. Amirat, G. Yao, J. Han, and H. Mangel, "Second-order sliding mode control for DFIG-based wind turbines fault ride-through capability enhancement," ISA Transactions, vol. 53, no. 3, pp. 827-833, 2014.

[16] B. Beltran, M. E. H. Benbouzid, and T. Ahmed-Ali, "Secondorder sliding mode control of a doubly fed induction generator driven wind turbine," IEEE Transactions on Energy Conversion, vol. 27, no. 2, pp. 261-269, 2012.

[17] F. Z. Tria, K. Srairi, M. T. Benchouia, and M. E. H. Benbouzid, "An integral sliding mode controller with super-twisting algorithm for direct power control of wind generator based on a doubly fed induction generator," International Journal of Systems Assurance Engineering and Management, vol. 8, no. 4, pp. 762-769, 2017.
[18] Y. Errami, A. Obbadi, S. Sahnoun, and M. Benhmida, “Design and sliding mode control for PMSG based wind power system connected to a non-ideal grid voltages," in Proceedings of the 2015 3rd International Renewable and Sustainable Energy Conference (IRSEC), IEEE, 2015.

[19] A. Merabet, M. Aminul Islam, R. Beguenane, and H. Ibrahim, "Second-order sliding mode control for variable speed wind turbine experiment system," Renewable Energy and Power Quality Journal, vol. 12, pp. 1-5, 2014.

[20] J. Hostettler and X. Wang, "Sliding mode control of a permanent magnet synchronous generator for variable speed wind energy conversion systems," Systems Science \& Control Engineering, vol. 3, no. 1, pp. 453-459, 2015.

[21] S. Heier, Grid Integration of Wind Energy: Onshore and Offshore Conversion Systems, John Wiley \& Sons, 2014.

[22] M. Nasiri, J. Milimonfared, and S. H. Fathi, "Modeling, analysis and comparison of TSR and OTC methods for MPPT and power smoothing in permanent magnet synchronous generator-based wind turbines," Energy Conversion and Management, vol. 86, pp. 892-900, 2014.

[23] W. Perruquetti and J. P. Barbot, Sliding Mode Control in Engineering, vol. 11, M. Dekker, 2002.

[24] Y. Shtessel, C. Edwards, L. Fridman, and A. Levant, "Conventional sliding mode observers," in Sliding Mode Control and Observation, pp. 105-141, Springer, 2014.

[25] M. A. Abdullah, A. H. M. Yatim, C. W. Tan, and R. Saidur, "A review of maximum power point tracking algorithms for wind energy systems," Renewable \& Sustainable Energy Reviews, vol. 16, no. 5, pp. 3220-3227, 2012. 


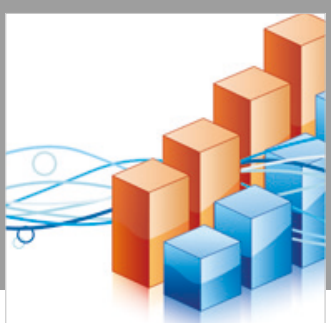

Advances in

Operations Research

\section{-n-m}
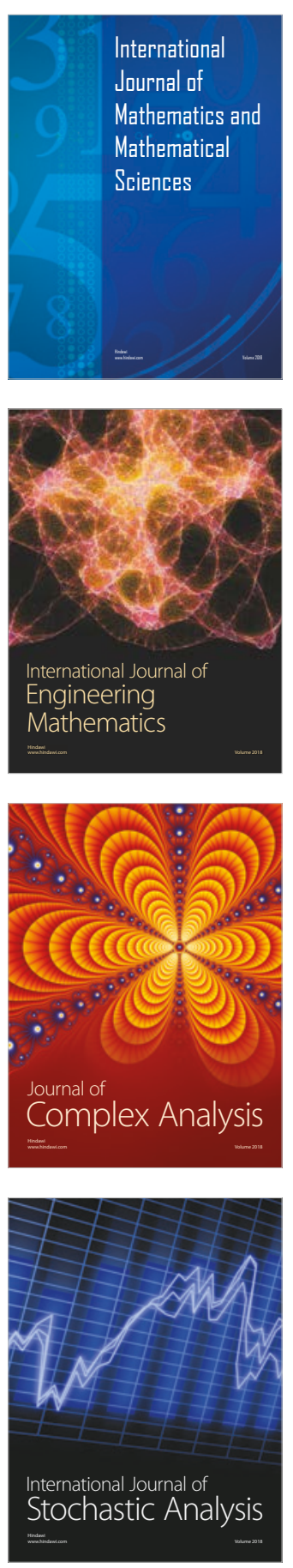
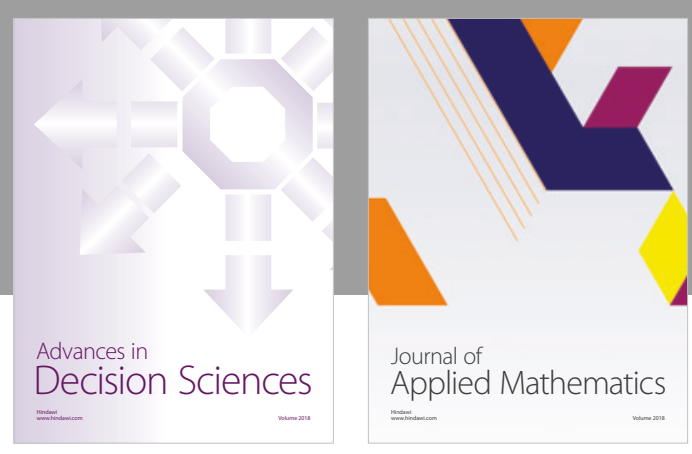

Journal of

Applied Mathematics
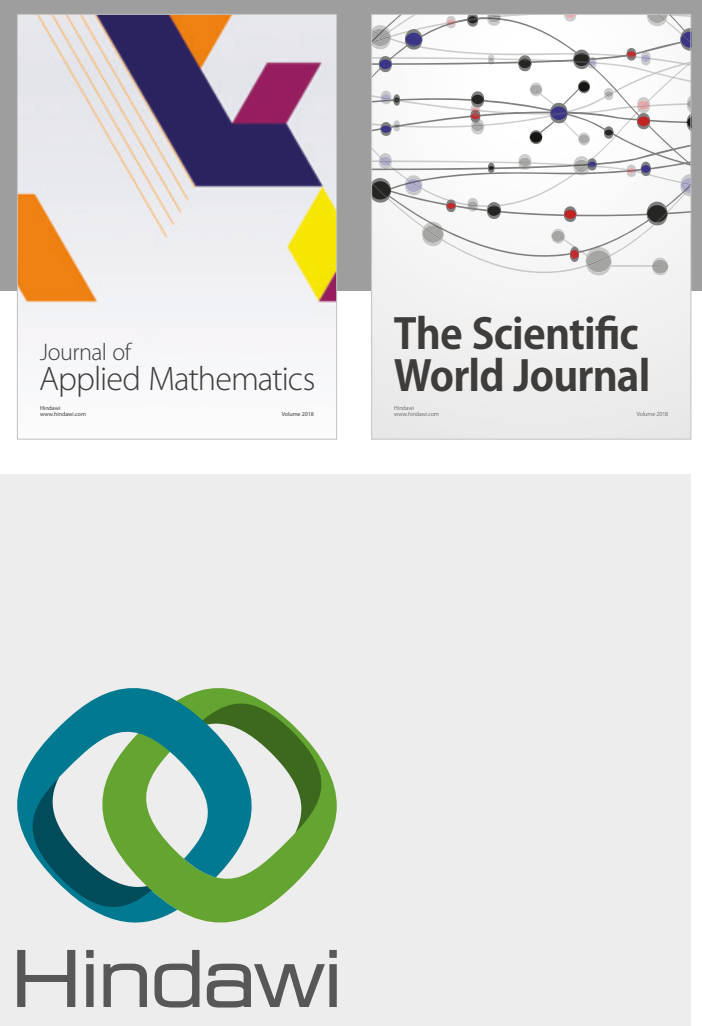

Submit your manuscripts at

www.hindawi.com

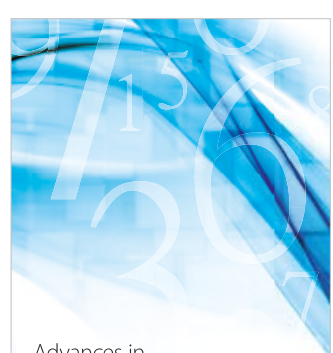

Advances in
Numerical Analysis
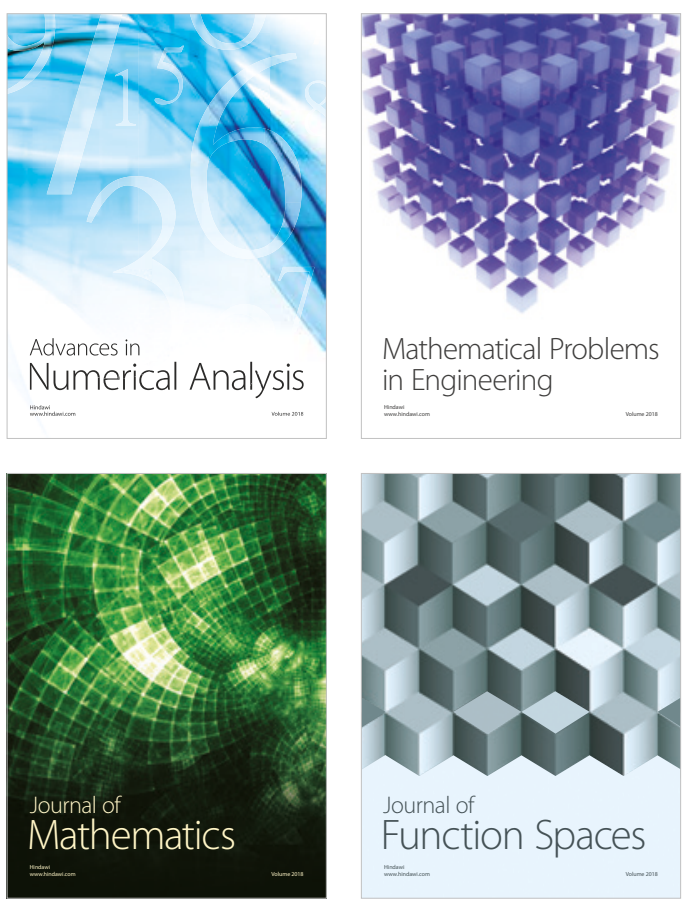

Mathematical Problems in Engineering

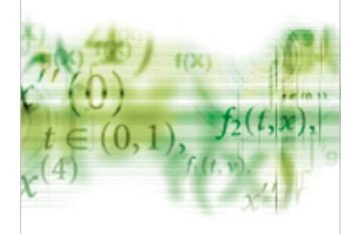

International Journal of

Differential Equations

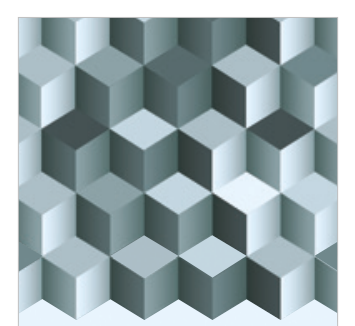

Journal of

Function Spaces
The Scientific

World Journal

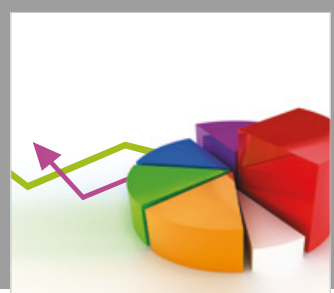

Journal of

Probability and Statistics
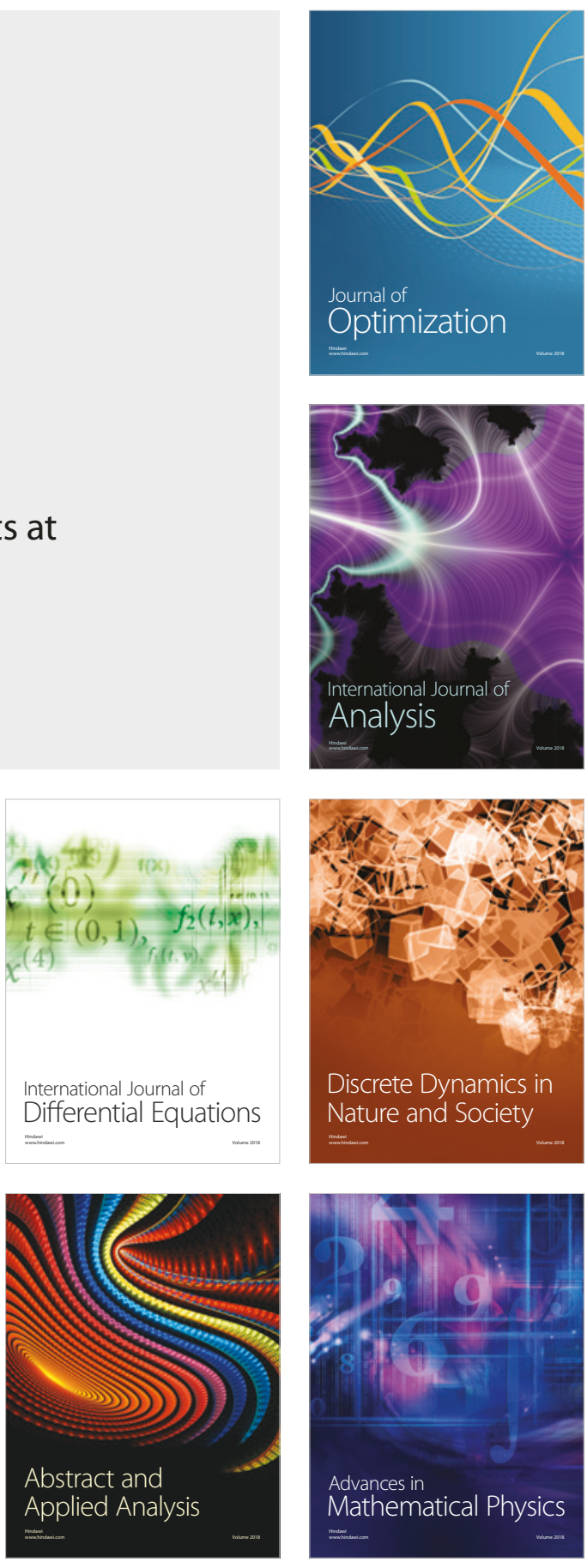